\title{
A report on diversity and distribution of macrofungi in the Garhwal Himalaya, Uttarakhand, India
}

\author{
Kamal C. Semwal ${ }^{1 *} \&$ Vinod K. Bhatt ${ }^{2}$ \\ ${ }^{1}$ Department of Biology, College of Sciences, Eritrea Institute of Technology, P. Box 12676, Mai Nefhi, Asmara, Eritrea (East Africa) \\ ${ }^{2}$ Navdanya Reserach Foundation, 105, Rajpur Road, Dehradun, Uttarakhand, India \\ * corresponding author (e-mail: kamalsemwal@gmail.com; ORCID: https://orcid.org/0000-0001-7748-8911)
}

\begin{abstract}
We report mycodiversity of the different forest types of the Garhwal Himalaya, Uttarakhand, India. The results drawn here are based on the study carried out in the different forest sites of the Garhwal Himalaya during the rainy season from 2013 to 2015 . We collected a total of 323 specimens, including 310 specimens belonging to Basidiomycota and 13 to Ascomycota. Furthermore, 212 specimens of Basidiomycota were identified and grouped into 33 families, 75 genera and 198 species, while 13 specimens of Ascomycota were grouped into 7 families, 7 genera and 11 species. 127 species were found in oak dominated temperate broadleaved forest, while 42 were collected from coniferous and 19 from the mixed woodland composed mainly of Quercus, Myrica, Rhododendron and Pinus trees in middle to higher hills, and Shorea robusta and Tectona grandis in the dipterocarp forests of lower hills. In terms of fungal species distribution in these forests, Amanitaceae, Russulaceae and Boletaceae were found most dominant in oak dominated forests, whereas Tricholomataceae and Cantharellaceae were commonly found in Pinus and Cedrus dominated forests and those belonging to family Cortinariaceae - in mixed forests. Species belonging to the families Agaricaceae, Amanitaceae and Tricholomataceae were found dominant in dipterocarp forest in the lower Himalayan region. The majority of species belonging to all families were found near lower to mid range altitude, which may result from the overlapping effect of atmospheric temperature and climate. The members of seven families, i.e., Russulaceae, Amanitaceae, Tricholomataceae, Boletaceae, Cantharellaceae, Cortinariaceae and Gomphaceae, were found as main ectomycorrhizal forming species from the elevation range of 500-2800 $\mathrm{m}$ a.s.l., in all four forest types.
\end{abstract}

Key words: Ascomycota, Basidiomycota, diversity, distribution, forest communities, Garhwal Himalaya, India

\section{Introduction}

Uttarakhand is one of the northwestern Himalayan states of India. It borders on Himachal Pradesh in the north-west, Uttar Pradesh in south, Nepal in south-east and China in north. It has two distinct politico-cultural provinces known as Garhwal and Kumaon. The state comprises 13 districts, namely: Chamoli, Dehradun, Haridwar, Pauri, Rudraprayag, Tehri, and Uttarkashi in the Garhwal province and Almora, Bageshwar, Champawat, Nainital, Pithoragarh and Udham Singh Nagar in the Kumaon province. Both provinces relish Shorea robusta tree dominated forests in the lower Himalayan region and oak dominated forests with the admixture of such species as, among others: Betula, Rhododendron, and Myrica, in the higher Himalayan region of temperate zone, or with Cedrus and other coniferous trees, such as: Pinus, Taxus and Abies, in other altitudinal ranges
(Sharma \& Kumar 1991; Suyal et al. 2010; Semwal et al. 2014). These forests provide favorable conditions for the growth of various types of macrofungi (Semwal et al. 2014). Topographically Uttarakhand (28' $44^{\prime \prime} \mathrm{N}$ to $31^{\prime 2} 28^{\prime \prime} \mathrm{N}$ latitude and $77^{\prime} 34^{\prime \prime} \mathrm{E}$ to $81^{\prime} 03$ ' E longitude) encompasses an area of $53,485 \mathrm{~km}^{2}$., which accounts for nearly $15.5 \%$ of the total geographical area of western Himalayas. As much as $64.81 \%\left(34661.52 \mathrm{~km}^{2}\right)$ of the total geographical area of this state is covered by dense broadleaved and scattered coniferous forests (FSI 2003). These conditions favour the wood rotting fungi, as well fungi that aid wood stump degradation and, at the same time, are pathogens of living trees as well. Reports on the occurrence of macrofungi have been limited only to certain groups of the macrofungi found in the state, i.e., Amanita (Bhatt et al. 2003; Semwal 2003; Semwal et al. 2005, 2006, 2007), Russula and Lactarius (Das et al. 2002, 2003, 2004a, 2004b, 2005, 2006a, 2006b; Das 
\& Sharma 2001a, 2001b, 2002, 2003, 2004, 2005) and a few scattered reports on other groups of Agaricales (Semwal et al. 2018). But taking into account the total forest covered area, tree diversity and forest types, there is still a big potential for the study of macrofungi. The data presented herein will enhance the available information about the wild macrofungal diversity of the Uttarakhand state of India.

\section{Material and methods}

The diversity and distribution of the macromycetes recorded in the present study is based on the collections made during the years 2013 to 2015, in the different forest types of Uttarakhand (Fig. 1). The ecological data and fruit body photographs were recorded in nature with the aid of Nikon Coolpix P510, and morphological features were described from fresh material. Associated trees were also recorded and ectomycorrhizal connections traced after observation of roots. For microscopic studies, the dried material was revived in $3 \%$ aq. $\mathrm{KOH}$ or $10 \%$ aq. ammonia and microscopic structures were studied using 2\% Congo Red and 2\% phloxine. Melzer's reagent was also used to detect the amyloid and dextrinoid reaction of the spore wall for some specimens, where it was required to delimit the species in a particular taxonomic section. The spores were studied from the spore deposits as well as from the fresh material. Identification of sporocarps was aided with morphological and microscopic features that tallied with field guides and available taxonomic literature (Else \& Hvass 1978; Singer 1986; Lamaison \& Polese 2005; Binion et al. 2008; Phillips 2010).

All collected specimens are presently kept in the personal herbarium of the first author (KCS) with collection numbers, but ultimately, they will be deposited in the Hemwati Nandan Bahugna Garhwal University Herbarium (GUH), Srinagar Garhwal, Uttarakhand, India to obtain regular herbarium accession numbers. All the photographs are with the first author (KCS) in his digital photo depository.

The nomenclature of fungi used in this work follows different sources.

The nomenclature of tree species was given according to Suyal et al. (2010), Negi and Dhyani (2012), Bisht and Bhatt (2013) (Table 1).

\section{Results}

\subsection{List and characteristics of species}

Fungal expeditions to the Uttarakhand Himalaya during the rainy seasons of 2013 to 2015 provided data on macrofungal diversity and distribution in this region. A total of 323 specimens were collected, out of which 310 specimens belonged to Basidiomycota and 13 to Ascomycota. The detailed data about the number of specimens in each family and identified species were presented in the list below. In a few cases, the varieties of species found in the studied area are described. For most species, the following information was provided:

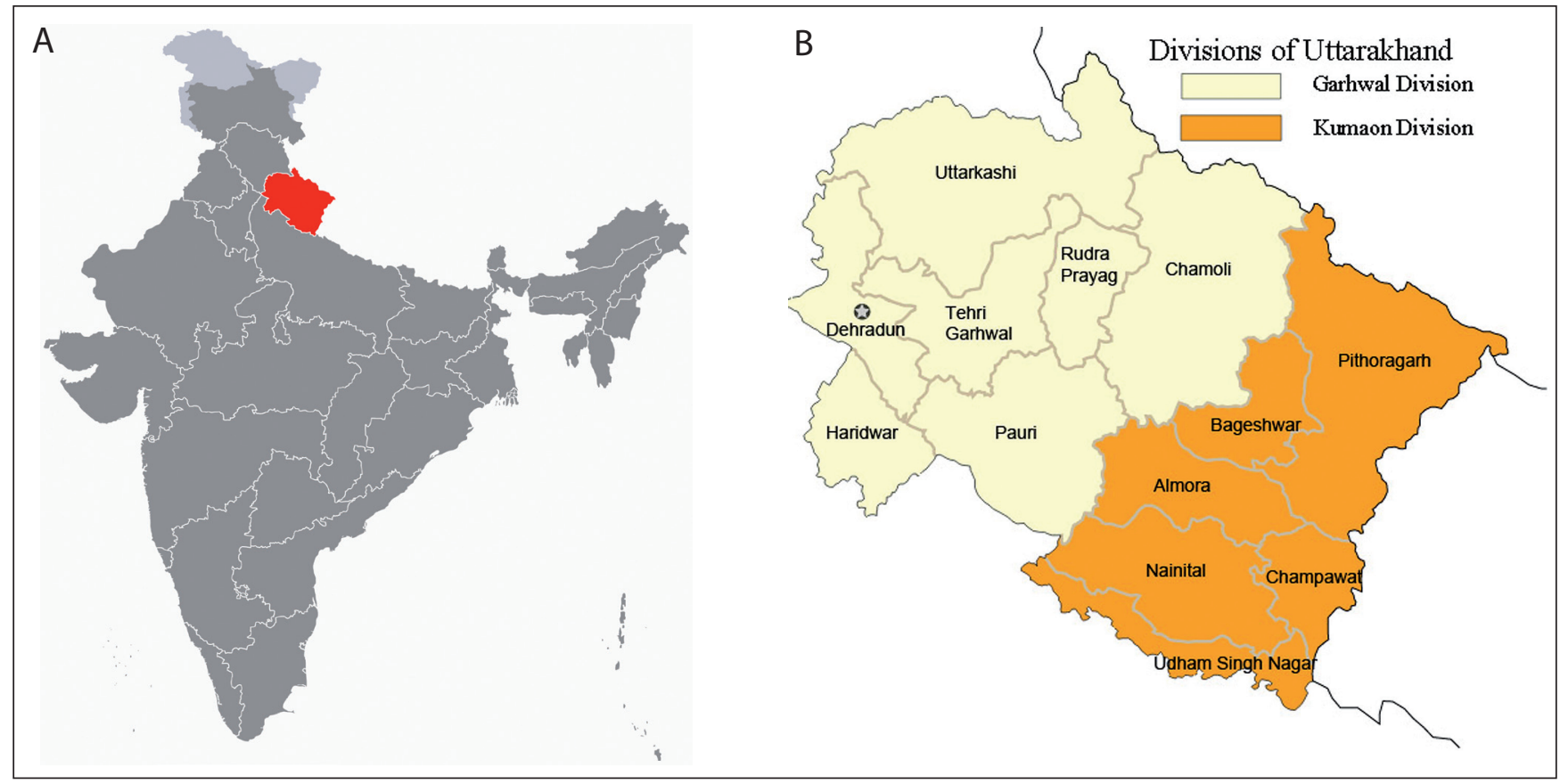

Fig. 1. Location of the Uttarakhand state in India (A) and the studied Garhwal Division (B) (source: https://en.wikipedia.org/wiki/Uttarakhand\#/ media/File:IN-UT.svg, https://commons.wikimedia.org/wiki/File:Kumaon_Garhwal.jpg) 
Table 1. List of major tree species in 4 types of forest communities occurring in the Garhwal Himalaya, with their ranges of altitude

\begin{tabular}{|c|c|c|c|}
\hline Forest Type & Major trees/ Shrubs & Local name & Elevation (m a.s.l.) \\
\hline \multirow[t]{5}{*}{ Coniferous } & Cedrus deodara [Roxb.] G. Don. & Devdar & $2000-3000$ \\
\hline & Pinus roxburghii Sarg. & Cheed & $1200-2000$ \\
\hline & P. wallichiana A.B. Jackson & Kail & $2100-2500$ \\
\hline & Cupressus torulosa D. Don ex Lamb. & Devidiyar & $2300-3300$ \\
\hline & $\begin{array}{l}\text { Taxus baccata L. subsp. wallichiana (Zucc.) } \\
\text { Pilger }\end{array}$ & Thuner & $2000-2600$ \\
\hline \multirow{14}{*}{$\begin{array}{l}\text { Broadleaved } \\
\text { Oak dominated }\end{array}$} & Quercus leucotrichophora A. Camus & Banj & $1850-2300$ \\
\hline & Q. semecarpifolia Smith & Kharsu & $2000-2500$ \\
\hline & Q. dilatata Lindle. ex Royle & Moru & $2000-2500$ \\
\hline & Q. floribunda, Lindl. ex A. Camus & Tilonz & $2000-2400$ \\
\hline & Rhododendron arboreum Smith & Buransh & $1800-2600$ \\
\hline & Rhododendron anthopogon D. Don & Son pati & above 3000 \\
\hline & Rhododendron campanulatum D. Don & Safed burans & above 3000 \\
\hline & Myrica esculenta Buch. Ham. ex. D. Don. & Kaafal & $1850-2500$ \\
\hline & Lyonia ovalifolia (Wall.) Drude & Anyar & $1850-2200$ \\
\hline & Betula utilis D. Don & Bhojpatra & $2500-3000$ \\
\hline & Aesculus indica (Wall. ex Camb.) Hook. & Pangar & $2300-2600$ \\
\hline & Cinnamomum tamala $\mathrm{T}$. Nees \& Eberm. & Daalchini or Tejpatar & $1900-2400$ \\
\hline & Corylus jacquemontii Decne. & Bhotia Badam & $2100-2600$ \\
\hline & Juglans regia $\mathrm{L}$. & Akhrot & $1750-2300$ \\
\hline \multirow[t]{4}{*}{ Dipterocarpus } & Shorea robusta Gaertn. & Sal & $400-1000$ \\
\hline & Tectona grandis Linn. & Sagonor Teak & $400-1000$ \\
\hline & Mallotus philippensis Muell. & Rohini & $400-1000$ \\
\hline & Bauhinia malabarica Roxb. & Gular or Kachnar & $400-1000$ \\
\hline Mixed & $\begin{array}{l}\text { In lower hills, major trees include Shorea robusta } \\
\text { Gaertn. (Sal), Tectona grandis Linn. (Teak), } \\
\text { Mallotus philippensis Muell. (Rohini), Bauhinia } \\
\text { malabarica Roxb. (Gular) and scattered pines. }\end{array}$ & & \\
\hline & $\begin{array}{l}\text { In higher hills, major trees included Lyonia } \\
\text { ovalifolia (Wall.-Ayanr), Aesculus indica (Wall. ex } \\
\text { Camb.) Hook. (Pangar), Quercus spp., Pinus spp., } \\
\text { Cupressus torulosa D. Don ex Lamb. (Devidayar), } \\
\text { and Cedrus deodara (Devdar). }\end{array}$ & & \\
\hline
\end{tabular}

morphological description, type of forest community and species of trees or shrubs with which they are associated and the height above sea level. The attention was drawn to species used for food. The list of species was supplemented with original photographs of some taxa (Appendix 1).

\section{ASCOMYCOTA}

Family: Leotiaceae

(Number of specimens: 2)

Leotia lubrica Fr. (App. 1/1); ascocarp irregular - cushion shaped or in the form of convoluted head, thick, wavy, viscid when wet, yellowish brown to ochraceous yellow, stem terete, yellowish, often mealygranulated.

Distribution: grows in soil, among moss, in coniferous and broadleaved forest, under Cupressus torulosa and oak trees, in elevation range from 1900$2300 \mathrm{~m}$ a.s.1.; solitary.

Leotia cf. viscosa Fr. (App. 1/2); ascocarp irregular hemispheric and convoluted head, wavy, viscid when wet, dull olive green, stem terete, grayish green, often mealy-granulated, hollow.

Distribution: grows in soil, among moss, in broadleaved forest under the canopy of Quercus leucotrichophora, in elevation range from $1900 \mathrm{~m}$ a.s.l; in groups. 
Family: Helvellaceae

(Number of specimens: 4)

Helvella elastica Bull.; ascocarp small, saddle shaped, appeared depressed, with 2-4 lobes, free to adnexed to stem, yellowish; stipewith ribs, hollow, twisted.

D is tribution: grows on ground in coniferous and broadleaved forest, under Cedrus deodara and oak trees, at elevation range from 1900-2300 $\mathrm{m}$ a.s.1.; among leaf litter, solitary.

Other species from the family Helvellaceae: Helvella lacunosa Afzel.

Family: Xylariaceae

(Number of specimens: 2)

Xylaria hypoxylon (L. ex Hooker) Grev.; fruit body (stroma) cylindric, then flattened with bifurcate or branched at apex, powdered white, lower part blackish hairy.

D i s tribut i o n: grows in dipterocarp forest, on dead tree stumps of Shorea robusta and Tectona grandis (600 $\mathrm{m}$ a.s.1.); in cluster or gregarious.

Xylaria polymorpha (Pers. ex Merat) Grev. (App. 1/3); fruit body (stroma) club-shaped, ended downwards as cylindric stalk, grayish black to blackish, surface granulated or roughened.

Distribution: grows on dead tree trunks of tree stumps of Shorea robusta and Tectona grandis, in dipterocarp forests (600 $\mathrm{m}$ a.s.1.); solitary or in cluster.

Family: Morchellaceae

(Number of specimens: 2)

Morchella esculenta (L.) Pers.; ascocarp small to medium, apothecia rounded to ovoid, sometimes elongated to conical, dull yellowish to yellowish brown, outer surface with irregular pits and ridges, ridged yellowish, grayish brown at maturity; stem creamish, wrinkled, often granulose.

Distribution: grows only in coniferous forests, under the canopy of Cedrus deodara and Cupressus torulosa, in elevation range from 1900-2300 m a.s.1., in humicolous soil. This mushroom occurrs during the months of March and April, only after lightning and thunder storms. This mushroom is highly prized and delicious to eat. Locally it is known as Guchhi, and villagers collect and consume it, and sell in dry season. Uses: delicious for eating and highly priced, also sold in market

Morchella conica (Pers.) Fr.; ascocarp small to medium, apothecia spindle-shaped to conical, wine brownish, with dark ridges; stem creamish, twisted or wrinkled, often granulose.
D i s tribution: grows only in coniferous forests, at elevation range from 1900-2300 m a.s.1., in humicolous soil associated with the leaf litter of Cedrus deodara and Cupressus torulosa. This mushroom has the same value as M. esculenta.

U s e s: edible and delicious.

\section{Family: Ophiocordycipitaceae (Number of specimens: 1)}

Ophiocordyceps nutans Pat. (App. 1/4); fruit body (stroma) or fertile head cylindrical, orangish red to orangish yellow; stem blackish downwards, light orangish red to whitish towards apex.

Distribution: grows in oak forest on the head or mouth of insects of Heteroptera (stink bugs). This mushroom differs from other fungal species in its growth habit, it grows at elevation range from 1900$2200 \mathrm{~m}$ a.s.l.

\section{Family: Pezizaceae}

(Number of specimens: 1)

Peziza badia Pers. (App. 1/5); ascocarp small, irregular, saucer- or cup-shaped, attached to the substrate, inner surface smooth, wine brown to browinish yellow, outer surface lighter in colour in comparision to inner surface.

Distribution: grows in mixed forest dominated by oak trees, in mid altitude; at elevation range from 1900-2200 m a.s.1.; solitary or gregarious.

Family: Pyronemataceae

(Number of specimens: 1)

Aleuria aurantia (Pers.) Fuckel (App. 1/6); ascocarp small, cup or disk shaped, inner surface orangishyellow, smooth, outer surface scurfy and having whitish hairs, light orangish-yellow.

D i s tribution: grows in an open area, among moss, at elevation range from 1900-2300 m a.s.1.; solitary or gregarious.

\section{BASIDIOMYCOTA}

Family: Amanitaceae

(Number of specimens: 43)

Amanita avellaneosquamosa (S. Imai) S. Imai; basidioma medium; cap convex to plano-convex, slightly depressed in the centre, white to milky white, covered with small brownish orange squamules; margin slightly striate, appendiculate; gills free, close; stem tapering upwards, white, pruinose to mealy, floccose 


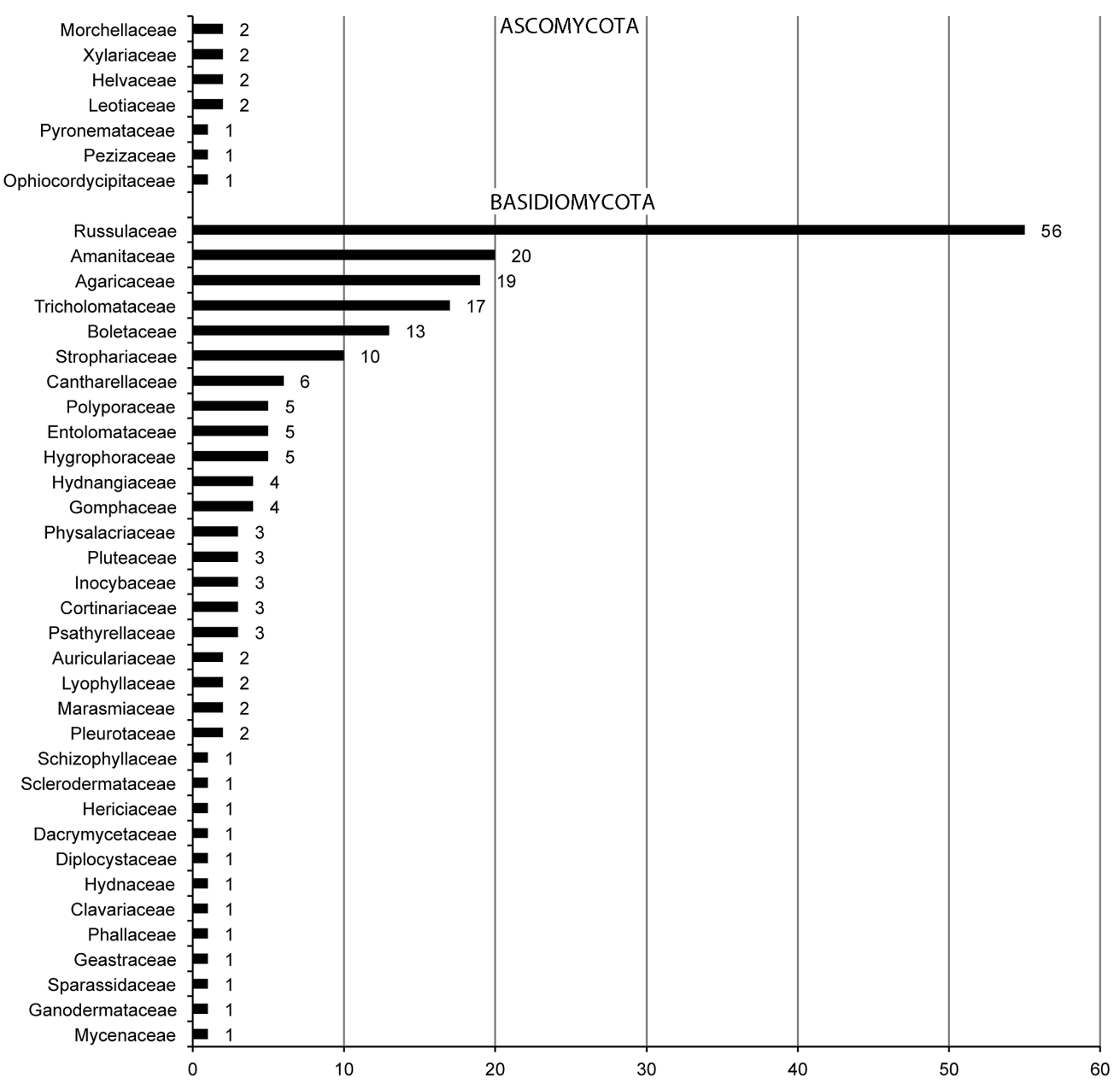

Fig. 2. Number of species in the families of macromycetes (Basidiomycota and Ascomycota) found in the area of Garhwal Himalaya, Uttarakhand, in the year 2013-2015

scaly at base; ring fugacious; volva saccate, with limbs. Distribution: Grows under pine and Myrica trees, in the elevation ranges from 1800-2000 m a.s.1.; solitary to scattered.

Amanita ceciliae (Berk. \& Br.) Bas (App. 1/7); basidioma medium to large; cap convex to planoconvex, finally plane, slightly depressed in the centre, grayish yellow to brownish orange, often covered with brownish gray to grayish brown, thin, floccose-felted patches; margin tuberculate-striate; gills free, close; stem densely decorated with gray to brownish gray fibrils; volval remnants on stipe base, blackish brown, ragged fragments in concentric rings.

Distribution: Grows in pine forest, under Pinus roxburghii, in the elevation ranges from 1800-2100 m a.s.1.; solitary to scattered.

Amanita chepangiana Tulloss \& Bhandary (App. 1/8); basidioma medium to very large; cap convex, plane with age, white to cream white; margin tuberculatestriate; gills free; stem white, with whitish appressed, zigzag arranged fibrils; ring superior; volva thick, saccate, often with limbs, very large.
Distribution: Common in dipterocarp forest, dominated by Shorea robusta and Tectona grandis, particularly at elevations from 600 to $1500 \mathrm{~m}$ a.s.1.; grows in soil, solitary to gregarious.

U s e s : Very commonly collected and eaten by local people.

Amanita concentrica T. Oda, C. Tanaka \& Tsuda (App. 1/9); basidioma medium to large; cap convex to planar with age, white to yellowish white, cream in middle, covered with white to yellowish pyramidal to conic volval warts; margin short-striate, appendiculate; gills free, white, crowded; stem subcylindric, white to off white, with large upward pointing, recurved scales at base; basal bulbfusiform, white; volval remnants on the upper part of the bulb as thick, recurved scales or warts, in 2-5 distinct ascending concentric rings; ring superior, membranous, whitish.

Distribution: Grows in coniferous and mixed forest, under oak, Rhododendron arboreum, Pinus roxburghii and Cupressus torulosa trees, in soil, in elevation range from 1900-2200 m a.s.1.; solitary to scattered. 
Amanita flavipes S. Imai (App. 1/10); basidioma medium to large; cap convex to plano-convex, and finally plane with age, brown, leather brown to light brown over disc, vivid yellow towards margin, covered with yolk yellow to grayish yellow irregular conic warts; gills free, whitish to yellowish; stem with yellowish white, finely ornamented appressed zigzag fibrils above annulus, pulverulent to mealy below; basal bulb ovate to sub-globose, covered with yellow to yolk yellow small floccose patches or friable warts; ring superior, membranous, yolk yellow.

Distribution: Grows in coniferous and mixed forests, under pine, Cupressus torulosa, Cedrus deodara, and oak trees, in the elevation range of 1900$2200 \mathrm{~m}$ a.s.1.; solitary to scattered.

Amanita fritillaria (Berk.) Sacc. (App. 1/11); basidioma medium to large; cap convex to plano-convex and finally plane, slightly depressed at disc, teak brown, to brown over disc, brown to brownish orange with radially innate fibrils towards margin, sometimes with small, brown floccose patches; gills free, close, white; stem white to orange white, covered with teak brown appressed ornamented fibrils; basal bulb subglobose to ovate, upper part covered with blackish brown, thin, floccose patches; ring superior, grayish brown; flesh turning pinkish red on cutting.

Distribution: Grows in broadleaved and mixed forest, under oak and pine trees, in the elevation range of 1800-2300 m a.s.l.; solitary to scattered.

Amanita griseofarinosa Hongo; basidioma medium to large; cap plano-convex to plane, orangish white to orangish grey, covered with brown to grayish brown or dark brown, small floccose-felted volval warts, margin appendiculate; gills free, whitish; stem grayish, covered with brownish gray to ash gray squamules; basal bulb pyriform, verrucose, white, with yellowish geay to orangish gray volval remnants; ring brownish gray, fugacious.

Distribution: Grows in broadleaved forests, under Cinnamomum tamala trees, 2200 m a.s.l.; solitary to scattered.

Amanita hemibapha (Berk. \& Broome) Sacc. (App. 1/12); basidioma medium to large, cap plane with age, deep orange to orange red, deep yellow to yellowish, with a tuberculate-sulcate striate margin; gills free, of various lengths, pastel yellow to yellowish; stem yellowish orange to deep yellow, with appressed zigzag arranged fibrils; ring superior; volva saccate, often with 2-3 limbs. Distribution: Fairly common in broadleaved, mixed and coniferous forest, under oak, Lyonia ovalifolia, Rhododendron. arboreum, Myrica esculenta and Pinus roxburghii trees, in elevation range from 600$2200 \mathrm{~m}$ a.s.1.; grows solitary to scattered.

U s e s: Edible, commonly eaten by local villagers, Nepali and Tibetan peoples.
Amanita oberwinklerana Zhu L. Yang \& Yoshim. Doi; basidioma medium to large; cap plano-convex, plane with age, white to whitish, concolourous, glabrous, volval remnants sometimes present in the form of a single white membranous patch; margin smooth nonappendiculate; gills free, white, close to crowded; stem slightly tapering upwards, white to whitish, glabrous to floccose at below; ring superior, thin, whitish with pinkish brown tinge, pendant, membranous or friable; bulb subglobose to ovoid; volva limbate, 2-3limbs, subglobose to ovate, membranous, white.

Distribution: Fairly common in mixed broadleaved forests, under oak, Rhododendron and Myrica trees, elevation range from 1800-2300 m a.s.1.; solitary to scattered.

Amanita orientigemmata Zhu L. Yang \& Yoshim. Doi (App. 1/13); basidioma medium; cap convex to plano-convex, finally plane, slightly depressed at centre, grayish yellow to pale yellow or cream, covered with whitish to dirty white or yellowish white, small, randomly arranged floccose-felted to cottony patches volval remnants, margin tuberculate-striate; gills free, close, white to pale cream; stem white to yellowish white with very few appressed fine ornamented fibrils above the annulus; volva short appressed-limbate, sometimes in the form of floccose or felted patches or warts near apex of basal bulb, white to pallid; ring whitish to yellowish, with golden yellowish edge.

D is tribution: Grows in coniferous forests, under Cedrus deodara (2200 m a.s.1.); solitary to gregarious.

Amanita ovalispora Boedijin (App. 1/14); basidioma medium to large; cap plano-convex, plane with age, smoky brown to mouse grey over disc, grayish brown outwards, with a striate margin; gills free; stem covered with grayish fibrils; volva saccate, often with 2-3 limbs. Distribution: Grows in broadleaved forest dominated by oak trees, among the grass, solitary.

Amanita pseudoporphyria Hongo (App. 1/15); basidioma medium to large; cap convex, finally plane with age, grayish brown to brown, dark brown over disc, darker innate fibrils towards margin; margin nonstriate; gills free, close, white to whitish; stem white to whitish, base slightly bulbous; volva limbate, with 2-3 limbs, white, dirty white; ring white.

Distribution: Common in broadleaved forests under Quercus leucotrichophora, Rhododendron arboreum, Lyonia ovalifolia, and Myrica esculenta, or in the mixed forest dominated by Pinus roxburghii; grows on the ground, in elevation range from 1800-2200 $\mathrm{m}$ a.s.1.; solitary to gregarious.

Amanita rubrovolvata S. Imai (App. 1/16); basidioma small to medium; cap convex, finally plane, dark red to vivid red to reddish orange over disc, becoming paler towards margin, volval remnants orange-red to yellowish red, pulverulent-floccose to mealy; margin distinctly 
striate; gills free, close, yellowish white to cream; stem covered with light orange-yellow appressed fibrils, basal bulb pyriform; volval remnants on apex of bulb as reddish orange to yellowish orange to vivid red, pulverulentfloccose, felted, small patches, forming 2-3 incomplete concentric rings; ring superior, yellowish orange.

Distribution: Grows in broadleaved forest, dominated by oak trees; in soil, in elvation range from 1900-2200 m a.s.1.; solitary to scattered.

Amanita sinensis Zhu L. Yang (App. 1/17); basidioma medium to large; cap plano-convex to plane, slightly umbonate at centre, yellowish gray to orangish gray, darker in the middle, covered with grayish brown sub-conic volval warts, becoming floccose to pulverulent towards margin, with striate margin; gills free, close, whitish to cream; stem grayish to ashy, upper part covered with fine, grayish white scales or thick pulverulent remnants; basal bulb pyriform, whitish, with grayish brown volval remnants; ring grayish white, fugacious.

D istribution: Grows in broadleaved forest, under Cinnamomum tamala and oak trees (2200 m a.s.1.); solitary to scattered.

Amanita subglobosa Zhu L. Yang (App. 1/18); basidioma medium to large; cap convex to planoconvex, then plane, leather brown to tan over disc, brown to brownish orange to grayish orange outside, covered with white to dirty white small pyramidal to irregularly conic warts, margin tuberculate-striate; gills free, close, white to cream; stem white, more or less floccose-fibrillose or squamules below annulus; basal bulb whitish, subglobose to pyriform, bearing volval remnants as rolled-collar or short limb; ring white to yellowish white with brown to light brown edge.

Distribution: Terrestrial, commonly grows in coniferous and mixed forests, under Cedrus deodara, Cupressus torulosa, pine and oak trees, in elvation range from 1900-2300 m a.s.l.; solitary to gregarious.

Amanita subjunquillea S. Imai - occurs in two varieties:

- var. alba Zhu L. Yang; basidioma medium to large; cap convex to plano-convex, plane with age, bright white to milky white, sometimes pale cream to pale yellowish at disc, sub-viscid, glabrous and usually without volval remnant, when present in the form of a single, white to whitish membranous patch; margin smooth or sometimes faintly striate, nonappendiculate; gills free, white, close to crowded, lamellulae attenuate, of various lengths; stem tapering upwards, with apex slightly expanded, white to whitish, glabrous or with white, appressed fibrils or squamules; ring superior, thin, white, pendant, membranous or friable; bulb subglobose to ovoid; volva limbate, with 2-3limbs, subglobose to ovate, membranous, white.
Distribution: Grows in mixed broadleaved forests, under oak, Rhododendron and Myrica trees, in elevation range from 1900-2200 m a.s.l.; solitary to scattered.

- var. subjunquillea S. Imai; basidioma medium to large; cap convex to plano-convex, nearly plane with age, dark yellow, yellowish brown to brownish yellow or golden brown at disc, yellowish to citrin yellow or vivid yellow towards margin, with fine innate radial fibrils, viscid when wet, glabrous; margin smooth, or sometimes faintly striate, non-appendiculate; cap usually without volval remnants. Gills free, crowded to close, creamish white; stem tapering upwards, cylindric, whitish to yellowish with orangish brown fibrils or small scales, base slightly bulbous; ring superior, pendant, persistent, thin, membranous, yellowish white; volva limbate with 3-4 limbs, white, membranous.

Distribution: Grows in mixed broadleaved forests, under oak, Rhododendron and Myrica trees, in elvation range from 2100-2300 m a.s.l.; solitary to scattered.

Amanita umbrinolutea (Secr. ex Gill.) Bataille; basidioma medium to large; cap convex, finally plane with age, distinctly zonate with brownish orange centre, light brown at mid zone, brownish orange outwards; margin sulcate-striate; gills free, close; stem dirty white, covered with brownish orange fibrillose-squamules; volva saccate, often with brownish spots, with 2-3 limbs, membranous.

D is tribution: Grows in mixed forests, under oak and pine trees, in elevation range from 1800-2200 m a.s.l.; solitary to scattered.

Amanita vaginata (Bull.) Lam.; basidioma small to medium; cap convex to plano-convex, plane with age, slightly umbonate, grayish brown to brown over the disc, becoming light grayish brown to brownish grey outwards, with a strongly tuberculate-striate margin; gills free, whitish; stem with whitish to grayish white appressed, zigzag arranged fibrils, exannulate; volva saccate, membranous with 2-3 lobes.

Distribution: Grows in coniferous and mixed forests, under pine and oak trees, in soil, in elevation range from 1800-2100 $\mathrm{m}$ a.s.l.; solitary to scattered.

U s e s : Edible in some parts of the Garhwal region.

Other species from the family Amanitaceae: Amanita pseudovaginata Hongo; A. velatipes G. F. Atk.

Family: Hygrophoraceae

(Number of specimens: 13)

Hygrocybe conica (Schaeff.) P. Kumm.; basidioma small; cap conic, umbonate, surface distinctly innately streaked, reddish orange to yellowish green, bruising black, becoming blackish with handling and age; gills 
seceding to adnexed, close, yellowish; stem cylindric with twisted or lined striation, fibrous, yellowish orange, blackening on bruising.

Distribution: Grows in coniferous and mixed forests, under pine and oak trees (2200 m a.s.l.); on ground, solitary to scattered.

Hygrocybe chlorophana (Fr.) Wünsche (App. 1/19); basidioma small; cap convex, later applanate with slight depression in the middle, surface innately streaked, viscid, yellowish to lemon yellowish; gills adnate to slightly decurrent, fairly distant, yellowish; stem cylindric, twisted, compressed, smooth, concolorous with the cap.

D i s tribution: Grows in open areas, among moss in mixed forests (2300 $\mathrm{m}$ a.s.1.); solitary to scattered.

Other species from the family Hygrophoraceae: Hygrocybe miniata (Fr.) P. Kumm.; H. psittacina (Schaeff.) Herink.

Family: Russulaceae

(Number of specimens: 56)

Lactarius azonites (Bull.) Fr.; basidioma small to medium; cap convex, plane with age, often slight depression in the middle, grayish brown to dark brown, glabrous to thin velvety; gills adnate to subdecurrent, close, yellowish white, reddening on bruising; stem concolorous with the cap, surface pruinose at the base; latex white, milky, qucikly turning reddish upon bruising.

D is tribution: Grows in broadleaved forest, under oak trees, in elevation range from 1800-2100 m a.s.l.; solitary.

U s e s: People collect and eat this mushroom in the Garhwal region.

Lactarius camphoratus (Bull.) Fr.; basidioma small; cap convex to plano-convex with acute umbo in the middle, reddish brown; gills adnate to subdecurrent, close, orange white to pale orange; stem equal, slender, concolorous with the cap; latex milk-white or whey-like. D i s tribution: Grows in coniferous \& broadleaved forest, under Cedrus deodara and oak trees, in soil, in elevation range from $1800-2100 \mathrm{~m}$ a.s.1.; solitary to scattered.

U s e s: Local people collect and eat this mushroom.

Lactarius chrysorrheus Fr.; basidioma small to medium; cap convex, plane with age with slight depression in the middle, orangish yellow to ochre-buff; gills adnate to subdecurrent, crowded, pale orange; stem equal, often concolorous with the cap; latex white, turns yellowish. Distribution: Grows in mixed and broadleaved forest, under Cedrus deodara, pine and oak trees, in elevation range from 1800-2000 m a.s.1.; in soil, solitary.

Lactarius deliciosus (L.) Gray; basidioma medium to large; cap convex with depressed centre, grayish orange with yellowish tinge, with faint concentric rings of colour, often with greenish tinge spots or on bruising, margin often incurved; gills adnate, decurrent, crowded, dark orangish with grrenish tinge on bruising; stem equal, reddish orange, with olivaceous tinge; ltex orangish.

Distribution: Grows in coniferous forest, under Cedrus deodara and pine trees, in soil, in elevation range from 1800-2100 $\mathrm{m}$ a.s.l.; solitary.

Lactarius deterrimus $\mathrm{F}$. Gröger; basidioma medium to large; cap convex with a depression in the middle, orangish red to orange buff, staining olive green to purplish green; gills adnate to subdecurrent, close, orangish buff, staining reddish green; stem equal to tattered downwards, concolorous with the cap; latex orangish, quickly changes to purplish green.

Distribution: Grows in coniferous forest, under the trees of pine and Cupressus torulosa (2000 m a.sl.); in soil, scattered.

Lactarius fuliginosus (Fr.) Fr. (App. 1/20); basidioma small to medium; cap convex when young, becoming plano-convex to plane with depressed center, grayish brown to dark brown; gills adnate to subdecurrent, close, forked, white when young, becoming creamish with age; stem central, slightly tapering downwards, concolorous with the cap or slightly paler; latex white.

D is tribution: Grows under the trees of Quercus, Lyonia, Myrica and Rhododendron; on ground, in elevation range from 1800-2000 $\mathrm{m}$ a.s.l.; solitary or scattered.

Lactarius rufus (Fr.) Fr.; basidioma small to medium; cap convex with a depression, often with a small, broad umbo in the middle, plane with age, reddish brown to brick red; gills adnate to subdecurrent, crowded, whitish to pale yellowish; stem equal, slender, concolorous with the cap; latex milky-white.

D i s t r i but i o n: Grows in coniferous forest, among moss, under Cedrus deodara, in elevation range from 1800-2100 m a.s.l.; in soil, solitary to scattered.

Lactarius sanguifluus (Paul.) Fr.; basidioma medium to large; cap convex with a slight depression in the middle, surface zonate, reddish orange to wine red, often with greenish dots; gills adnate to subdecurrent, close, dull orangish; stem equal to tapered at the base, orangish buff, bruising greenish; latex dark reddish.

Distribution: Grows in coniferous forest, under Cedrus deodara and pine trees, in elevation range from 1900-2100 m a.s.1.; in soil, solitary to scattered.

Lactarius scrobiculatus (Fr.) Fr.; basidioma medium to large; cap convex when young, shallowly depressed in the center, becoming deeply depressed on maturity, cuticle peels easily, glutinous to viscid, yellow to yellow ochraceous, margins incurved when young; gills subdecurrent, crowded to close, yellowish white, darker when mature; stem slightly broader at base, hollow, 
yellowish white, surface pitted; latex copious, milky, becoming sulphur yellow on exposure.

D istribution: Under coniferous trees-Cedrus deodara and Cupressus torulosa, in elevation range from 1800-2100 m a.s.1.; solitary to scattered, or gregarious in soil.

Lactarius subdulcis (Pers. ex Fr.) Gray; basidioma small to medium; cap convex when young, becoming shallowly funnel shaped, greyish yellow when young, becoming vinaceous buff to wine yellow; gills adnate to subdecurrent, close, yellowish white to buff, darker with age; stem equal, central, slightely tapering towards the base, concolorous with the cap, slightly paler with age; latex white, unchanging, slightly spotting the gills to vinaceous brownish or burgundy.

D i s tribution: Under the broadleaved forest trees of Myrica, Quercus and Rhododendron, in elevation range from 1800-2000 $\mathrm{m}$ a.s.l.; in soil, solitary, scattered.

Lactarius subindigo Verbeken \& E. Horak (App. $1 / 21$ ); basidioma small to medium; cap convex, with depressed centre, plane with age, yellowish in the middle, fading outwards with indigo blue concentric bands; gills adnate to subdecurrent, crowded, bluish, greenish blue on bruising; stem equal to tapered downwards, concolorous with the cap, with spotted dark at times; latex bluish, becoming dark green on exposure to air.

D is tribution: Grows in broadleaved forest, under oak, Rhododendrum arboreum, Myrica esculenta, and Cinnamomum tamala trees, in elevation range from 1800-2200 m a.s.1.; in soil, solitary to gregarious.

Lactarius subpurpureus Peck.; basidioma medium; cap convex, plane with age with a deep depression in the middle, light grayish red to grayish orange, viscid when wet; gills adnate to subdecurrent, crowded, purplish green, darker on bruising; stem equal, concolorous with the cap, somewhat scrobiculate; latex greenish blue.

Distribution: Grows in coniferous forest, under pine, Cedrus deodara, in elevation range from 1800 $2100 \mathrm{~m}$ a.s.l.; in soil, solitary.

Lactarius yazooensis Hesler \& A. H. Smith; basidioma small to medium; cap convex when young with depression in the center, becoming deeply depressed to infundibuliform, surface viscid, glabrous, zonate, orange to dark orange alternating with light orange to paler zones; gills adnate to subdecurrent, crowded, thin, forked, pale yellow becoming wine yellow to vinaceous brown or burgundy with age; stem central, cylindrical or slightly tapering downwards, concolorous with the cap, hollowing with age; latex white, milky, copious, unchanging, very acrid.

D istribution: Found in broadleaved and mixed forests under the trees of Myrica, Quercus,
Rhododendron and Pinus, in elevation range from 1900$2100 \mathrm{~m}$ a.s.l.; solitary, scattered, in soil.

Lactarius zonarius (Bull.) Fr.; basidioma small to medium; cap convex when young with shallow depression in the center, becoming deeply depressed and infundibuliform on maturity, light orange, concentrically zonate with alternate lighter and darker orange coloured zones; gills subdecurrent to decurrent, close, broad, light orange, milky latex exudes out when bruised; stem central, equal, hollow, light orange; latex white, copious, very acrid, unchanging.

D i s tr i b u ti o n: Grows in broadleaved forest, under Lyonia, oaks and Myrica esculenta, in elevation range from 1900-2200 m a.s.1.; in soil, solitary to scattered.

- var. riparius Hesler \& A. H. Sm. (App. 1/22); basidioma medium; cap convex at first, becoming shallow infundibuliform, white to creamish, margin inrolled; gills subdecurrent, crowded, creamish yellow; stem equal, concolourous with the cap, sometimes scrobiculate; latex creamish.

Distribution: Grows in coniferous and broadleaved forest, under Cedrus deodara, oaks and Myrica esculenta, in soil, solitary to scattered to gregarious.

Lactifluus corrugis (Pk.) Kuntze; basidioma small to large; cap convex with depressed disc, dark reddish brown; gills subdecurrent, close to subdistant, pale yellowish; stem equal to tapering downwards, grayish brown; latex white.

Distribution: Grows in coniferous, mixed and broadleaved forest, under oaks, Myrica esculenta and Cedrus deodara, in elevation range from 1800-2000 m a.s.1.; in soil, solitary.

Lactifluus hygrophoroides (Berk. \& M. A. Curtis) Kuntze; basidioma small to medium; cap convex, becoming applanate with age with depressed centre, yellowish brown; gills adnate, subdecurrent, distant, white to creamish; stem equal, pale orangish brown; latex white.

D i s tribution: Grows in broadleaved forest, under oak trees, in soil (2000 m a.s.l); solitary.

U s e s: Edible in some areas of Garhwal Himalaya.

Lactifluus hygrophoroides occurs in three varieties:

- var. lavandulaceous Hesler \& Smith; basidioma small to medium; cap convex when young, becoming plano-convex to plane with depressed centre, corrugated with age; light orange to sub ferruginous, finally ochraceous; gills subdecurrent to decurrent distant, pale yellow to highly ochraceous, staining pink to greyish brown when bruised; stem central, cylindrical or slightly tapering towards the base, concolorous with the cap or slightly pale; latex milky white.

Distribution: Found in broadleaved forests mostly under the trees of Quercus, also found under Lyonia and Rhododendron (2000 m a.s.1.); solitary to scattered, in humicolous soil. 
U s e s : Edible in some areas of Garhwal Himalaya. - var. odoratus Hesler \& A.H. Sm.; basidioma medium; cap convex, with depressed centre, apricot buff to light brownish; gills adnate to subdistant, whitish, staining the gills pinkish grey; stem equal, concolorous with the cap; latex white, unchanging.

D istribution: Grows in broadleaved, mixed or coniferous forests, under the trees of Lyonia ovalifolia, Myrica, Rhododendron, pine and Cedrus deodara, in elevation range from 1900-2100 m a.s.1.; in soil, scattered.

U s e s : Edible in some areas of Garhwal Himalaya. - var. rugatus Hesler \& Smith; basidioma small to medium; cap convex at first, becoming plano-convex to plane with age, with slight depression in the center, rusty to brownish organge; gills subdecurrent, distant, thick and rigid, cream to ochraceous, finally golden yellow, changing to brownish on bruising; stem equal slightly tapering towards the base, concolorous with the cap or slightly paler; latex mild, copious white but opaque.

D istribution: Grows in broadleaved or mixed forests, under the trees of Cedrus deodara, Cupressus torulosa, Pinus wallichiana A.B. Jacks and Rhododendron trees, in soil, in elevation range from 1800-2100 m a.s.l.; solitary to scattered.

U s e s: Edible in some areas of Garhwal Himalaya.

Lactifluus glaucescens (Crossl.) Verbeken; basidioma medium; cap convex, with depressed centre, plane with age, margin incurved with age, off whitish, darker as yellowish brown in the middle; gills subdecurrent, crowded, creamish; stem equal to tapered downwards, concolourous with the cap; latex creamish.

Distribution: Grows in broadleaved forest, among moss, under oak trees, in soil, solitary.

Lactifluus piperatus (L.) Roussel (App. 1/23); basidioma medium to large; cap convex, with broadly infundibuliform, centre, plane with age, whitish to yellowish white; gills subdecurrent, crowded, white; stem equal to tapered downwards, whitish; latex white, turning yellowish white.

Distribution: Grows in soil, in coniferous and broadleaved forest, under Cedrus deodara and oak trees, in elevation range from 1800-2000 m a.s.l.; solitary to scattered.

Lactifluus volemus (Fr.) Fr.; basidioma small to medium; cap convex when young, becoming plane to infundibuliform with age, brownish orange, margins sometimes splitting with age; gills subdecurrent, close, moderately broad, yellowish white, staining brown or brownish on bruising, lamellulae present in 2-3 tiers; stem central, cylindrical, slightly tapering, downwards, solid, concolorous with stipe; latex copious, white, unchanging, staining the tissue brown.
D i stribution: In mixed and broadleaved forests, under the trees of Quercus, Cedrus and Rhododendron, in elevation range from 1800-2000 m a.s.l.; solitary, scattered to gregarious, in soil.

- var. flavus Hesler \& Smith; basidioma small; cap convex when young, becoming plano-convex with slightly depressed center, greyish yellow; gills subdecurrent to decurrent, close, yellowish white, changing to reddish brown on bruising; stem central, cylindrical or slightly tapering downwards, concolorous with the cap or slightly paler, glabrous, staining ochraceous or tan at places; latex white, copious, sticky, unchanging, staining tissues brown.

Distribution: In mixed and broadleaved forests, under the trees of Quercus, Rhododendron and Cedrus, in elevation range from 1900-2100 m a.s.1.; solitary to scattered on the ground.

U s e s: Edible and good, consumed in Garhwal.

Russula adusta (Pers.) Fr.; basidioma medium to large; cap convex to applanate, depressed in the middle, dirty white to light brownish; gills creamish, densely crowded, brownish on handling; stem equal, whitish, dark on bruising.

D istribution: Grows in coniferous forests, under Cedrus, Cupressus and pine trees, in elevation range from 1900-2100 m a.s.1.; in soil, solitary to scattered.

Russula aeruginea Lindble ex Fr.; basidioma small to medium; cap convex when young, becoming planoconvex to plane with a shallow depression in the center, sometimes infundibuliform, olive green or grass green on maturity; gills adnexed to adnate or subdecurrent, close, yellowish white; stem equal or slightly tapering towards the base, yellowish white.

D is tribution: Grows in rich humus, broadleaved and mixed forests, under the trees of Cedrus, Cupressus, Myrica, Pinus, Quercus and Rhododendron, in elevation range from 1800-2100 m a.s.l.; solitary and scattered. U s e s: Edible in literature, not eaten by local people.

Russula amoenolens Romagnesi (App. 1/24); basidioma small to medium; cap convex to plane with depressed centre, grayish brown, centre darker, margin tuberculate, sulcate-striate; stem whitish, equal, brittle. D istribution: grows in coniferous, broadleaved and mixed forests, under pine, Cedrus deodara, Myrica, Lyonia and oak trees, in elevation range from 1800-2200 $\mathrm{m}$ a.s.l.; in soil, solitary to scattered.

Russula atropurpurea (Krombh.) Britz. (App. $1 / 25$ ); basidioma small to medium; cap convex when young, becoming plano-convex to plane, with a shallow depression in the center, violet brown in the middle, light burgundy towards outside; gills adnexed to adnate, subdistant, whitish; stem equal or slightly tapering towards the base, white.

D i stribution: grows in rich humus, in broadleaved and mixed forests, among Seleginella plants., under 
the trees of Quercus, Myrica and Rhododendron, in elevation range from 1800-2200 m a.s.l.; solitary and scattered.

Russula brevipes Pk. (App. 1/26); basidioma medium to large; cap convex with depressed centre and incurved margin, whitish, often covered with soil particles due to the growth habit; gills adnate, sub-distant, close, creamish; stem equal, whitish, brittle.

Distribution: grows in broadleaved or mixed forests, under Cedrus, pine and oak trees, in elevation range from 1800-2200 $\mathrm{m}$ a.s.l.; widely distributed, in soil, solitary to scattered.

Us e s: edible, good, eaten by the local people in Garhwal

- var. acrior Shaffer; basidioma medium to slightly large; cap convex when young becoming plano-convex to plane, depressed in center, cracking into aerolate patches with age, white to light buff when young, staining ochraceous to tan at places on maturity; gills narrow to moderately broad, adnate to subdecurrent or subdecurrent, close, forked near the stem, pale yellow, flushed with pale yellow tinge on the edge; stem concolorous with the cap.

Distribution: grows in mixed coniferous and deciduous forests, under the trees of Alnus, Cedrus, Cupressus, Lyonia, Myrica, Pinus, Quercus and Rhododendron, in elevation range from 1900-2100 m a.s.l.; solitary, scattered, in soil.

Russula compacta Frost \& Peck.; basidioma medium to large; cap convex, flattened with age, whitish to dark brownish yellow, turned rusty brown on bruising; gills crowded, adnate, creamish yellow, stained on bruising; stem cylindrical, whitish.

D istribution: grows in mixed forests, under pine, Cupressus torulosa, and oak trees, in elevation range from 1800-2100 m a.s.1.; in soil, solitary to scattered.

Russula crusotosa Peck; basidioma small to medium; cap convex at first, becoming plano-convex to plane with a shallow depression in the center, cuticle thin, breaking with age, yellowish brown to olive brown or greyish yellow; gills adnate to adnexed, close to subdistant, seperable, yellowish white, unchanging on bruising; stem central, cylindrical, equal to slightly tapering downwards, white to yellowish white.

Distribution: grows in mixed coniferous and broadleaved forests, under Cedrus, Myrica, Quercus and Rhododendron trees, in elevation range from 1800$2100 \mathrm{~m}$ a.s.l.; solitary - scattered, in soil.

U s e s: edible, eaten by few people in the Garhwal district only.

Russula cyanoxantha (Schaeff.) Fr.; basidioma medium to large; cap convex with slightly depressed disc; light olive green with purple hue in the middle; gills close to crowded, whitish; stem cylindrical, firm, and whitish.
D i stribution: grows in mixed forest, under pine, Cedrus deodara, and oak trees, in elevation range from 2000-2200 m a.s.1.; in soil, solitary.

U s e s: edible in literature, not eaten by local people.

Russula delica Fr.; basidioma small to medium, cap convex when young, becoming plano-convex to plane with depressed center, white to dull white at first, at places staining ochraceous to tan on maturity; gills adnate, subdistant to distant, white at first, yellowish white on maturity; stem central, cylindrical, slightly tapering downwards, concolorous with the cap, unchanging on bruising.

D is tribution: grows in coniferous and broadleaved forests under the trees of Cedrus, Cupressus, Pine, Quercus and Rhododendron, in elevation range from 1800-2200 m a.s.l.; solitary to scattered in soil.

U s e s: edible, eaten by local people.

Russula densifolia Fr.; basidioma small to medium; cap convex finally funnel shaped, whitish to brownish or even blackish grey with age; gills subdecurrent, crowded, dull white to creamish, becoming blackish brown on maturity; stem central, cylindric, white, becoming brownish white or reddish grey with age.

Distribution: grows in coniferous or mixed forests, under Cedrus deodara, Pine and oak trees, in elevation range from 1800-2100 $\mathrm{m}$ a.s.1.; in soil, solitary to scattered.

Russula dissimulans Shaffer; basidioma small to medium; cap convex when young, depressed center, subinfundibuliform with age, slightly viscid when young, white to dull brown to black with age; gills adnexed to adnate or decurrent to subdecurrent, close to subdistant, whitish to yellowish white becoming dark with age, turning brick red to brown and finally to black on cutting and bruising; stem central, cylindrical or slightly tapering above, white changing to black on cutting and bruising, similar to the cap.

Distribution: grows in coniferous or mixed forests, under Cedrus deodara, Pinus and Quercus trees, in soil, in elevation range from 1800-2200 $\mathrm{m}$ a.s.1.; solitary to scattered.

Russula emetica (Schaeff. ex Fr.) Gray; basidioma medium; cap convex, applanate with age, often depressed centre, reddish to cherry red; gills adnexed, creamish, subdistant; stem equal, brittle, white.

Distribution: grows in broadleaved forests, among moss, under the trees of Alnus, Lyonia, Myrica, Quercus and Rhododendron, in elevation range from 1800-2200 m a.s.1.; in soil, solitary to scattered.

Russula flavida Frost \& Pk. (App. 1/27); basidioma medium; cap small to medium, convex to plane with age, yellowish to lemon yellow, orange yellow in the middle, margin tuberculate-striate; gills sub-distant to close, whitish; stem equal with clavate base, yellowish. 
D i s tribution: found in broadleaved forests, under oak, and Rhododendron trees, in elevation range from 1800-2100 m a.s.1.; in soil, solitary to scattered.

Russula foetens Pers. (App. 1/28); basidioma medium to large; cap convex, applanate with age, often depressed centre, orangish brown, glutinous with honey brown centre; margin striate with bumps; gills creamish, having brownish spots with age, subdistant; stem irregular club shaped at below, brittle, hollowing with age, yellowish white, unchanging.

D istribution: grows in broadleaved and coniferous forest, under Pine, Cedrus deodara, Juglans, Lyonia, Myrica and oak trees, in elevation range from 1900-2200 m a.s.1.; in soil, solitary.

Russula fragilis (Pers. ex Fr.) Fr.; basidioma small to medium; cap convex, with slight depressed centre, applanate with age, purplish to light violet; gills pale creamish, subdistant stem club-shaped at base, fragile, white.

D is tribution: grows in mixed forests, under Pine and oak trees, in elevation range from 1800-2000 m a.s.1.; in soil, solitary.

Russula krombholzii Shaffer; basidioma small to medium; cap becoming plano-convex to plane, center depressed with age, viscid when moist, greyish red or deep purplish red or greyish magenta; gills adnexed to adnate, close to subdistant, yellowish white when young, becoming pale yellow with age; stem equal or slightly tapering downwards, white often flushed with purplish tint, unchanging on bruising.

Distribution: grows in broadleaved and mixed forests under the trees of Quercus, Rhododendron, Cedrus and Pinus, in elevation range from 1800-2100 $\mathrm{m}$ a.s.l.; in soil, solitary to scattered.

U s e s: edible in literature, not eaten by local people.

Russula laurocerasi Melzer; basidioma small to medium; cap convex to applanate, shallowly depressed in center, cuticle slimy and shiny when wet, peels completely, light yellow to yellowish brown or yellowish orange, margin tuberculate striate; gills adnexed to adnate close to subdistant, yellowish white to pale orange or greyish orange with age; stem central, equal, slightly tapering downwards, concolorous with the cap.

Distribution: grows in broadleaved and coniferousforests under the trees of Quercus, Rhododendron, Myrica, Cedrus and Pinus, in elevation range from 1800-2100 m a.s.l.; scattered to solitary.

Russula lepida Fr. (App. 1/29); basidioma small; cap convex to plane with age, pinkish red, discolor or light in color with age, margin striate; gills adnate, close to sub-distant, whitish to creamish; stem cylindrical, attenuate at the base, whitish.

Distribution: grows in mixed forest, under oak, Pine and Cedrus deodara trees, in soil, in elevation range from 1900-2200 $\mathrm{m}$ a.s.l.; solitary to scattered.
U s e s : edible in some villages in Garhwal Himalaya.

Russula lutea (Huds. ex Fr.) Gray; basidioma small; cap convex when young becoming plane with age, center slightly depressed, glabrous, viscid when moist, deep yellow to golden yellow; gills adnexed to free, thin, close to subdistant, yellow to orange, unchanging; stem cylindrical, tapering upwards, white, solid when young, hollowing with age.

D i s tribution: grows in broadleaved forests under the trees of Lyonia ovalifolia, Myrica esculenta, Quercus leucotrichophora and Rhododendron arboretum, in elevation range from $1800-2100 \mathrm{~m}$ a.s.l.; solitary to scattered.

U s e s: edible in literature, not eaten by local people.

Russula mariae Peck; basidioma medium; cap convex to flattened, purplish to vine red, margin clearly broken, striate; gills crowded, forked, whitish; stem cylindrical, pinkish, yellowish to lemon yellow.

D i stribution: grows in mixed forests, under oak, Pine and Cedrus deodara, in elevation range from 1800$2100 \mathrm{~m}$ a.s.l.; in soil, solitary.

Russula nigricans Fr. (App. 1/30); basidioma medium to large; cap convex to applanate, with slightly depressed center, dirty white, changing brownish to black with age, turn reddish on handling and bruising; gills distant, adnate, creamish, staining blackish with age and on bruising; stem equal, dirty white, stained similar to the cap.

Distribution: grows in broadleaved and mixed forest, under Cedrus deodara, Pine and oak trees, in elevation range from 1900-2300 m a.s.1.; in soil, solitary to scattered.

Russula ochroleuca Fr.; basidioma small to medium; cap convex at first, becoming plano-convex to plane, peels completely, yellowish orange to orange; gills adnate to subdecurrent, close, yellowish white, unchanging on bruising; stem central tapering both upwards and downwards, white, becoming greyish white with age.

Distribution: grows in broadleaved and mixed forest, under Quercus, Myrica, Lyonia, Rhododendron and pine trees, in elevation range from 1800-2100 m a.s.1.; in soil, solitary and scattered.

Russula vesca Fr.; basidioma medium to large; cap convex to flattened with age, light pinkish red to light wine, margin faintly tuberculate striate; gills crowded, whitish; stem equal to tapered downwards, dirty white.

D i s tribution: grows in broadleaved forests, under oak trees (1900 m a.sl.); in soil, solitary.

Russula virescens (Schaeff.) Fr. (App. 1/31); basidioma medium to large; cap convex, applanate with age, greenish to olive with small patchy cracks; gills creamish white, distant; stem cylindrical with attenuate base, whitish. 
Distribution: grows in coniferous and mixed forest, under oak, Cedrus deodara and pine trees, in elevation range from 1900-2200 m a.s.l.; in soil, solitary. U s e s : edible in literature, not eaten by local people.

Russula xerampelina Fr.; basidioma medium to large; cap convex, flattened with age, dark vinaceous to dark reddish; gills creamish; close to distant; stem cylindrical, slightly tapering upwards, whitish.

Distribution: grows in mixed forest, under Cedrus deodara, pine and oak trees, in elevation range from 1800-2000 m a.s.l.;in soil, among moss, solitary to scattered.

U s e s : edible in literature, not eaten by local people.

Other species from the family Russulaceae: Lactarius deceptivus (Peck) Kuntze; Russula alachuana Murrill; $R$. decolorans Fr.; R. earlei Peck; R. gracilis Burl.; $R$. heterophylla (Fr.) Fr.; $R$. minutula Vel. var. minutula Vel.; $R$. ochroleucoides Kauffman; $R$. rosea Pers.; $R$. variata Banning; $R$. versicolor Schaeff; $R$. vesca Fr.

\section{Family: Agaricaceae}

(Number of specimens: 41)

Agaricus arvensis Schaeff.; basidioma medium to large; convex to plano-covex, finally plane, whitish, with small scales; gills free, crowded, pinkish at first, becoming chocolate-brown with maturity; stem equal, whitish; ring superior, double.

D i s tribution: grows in open area in meadows, and in forest outskirts, among the grass (2000 m a.s.1.); solitary.

Agaricus bisporus (Lange) Imbach; basidioma small to medium; cap convex to plano-covex, finally plane, whitish, with small brownish scales; gills free, crowded, pinkish at first, becoming dark brown with maturity; stem equal, whitish; ring superior.

Distribution: grows in open area in meadows, among the grass, in elevation range from 600-1200 m a.s.l.; solitary to scattered.

U se s: Local people identify this mushroom on the basis of its size and gill colour and then eat it.

Agaricus campestris L. (App. 1/32); basidioma small to medium; convex, plano-convex with age, white to faded brownish, appressed fibrilose, grayish brown over disc; gills free, pinkish at first, becoming chocolatebrown with maturity; stem white to grayish white, smooth to slightly fibrillose; stipe and flesh turned pinkish brown on bruising; ring superior, disappears quickly.

D i s tribution: grows in open area among the grass and in mixed forest with moss, in elevation range from 600-1200 m a.s.1.; solitary to scattered.

U s e s: local people identify this mushroom on the basis of its fennel odor and eat.

Agaricus silvicola (Vittad.) Peck; basidioma small to medium; cap convex to plano-convex, plane with age, whitish; gills free, pinkish at first, becoming chocolate- brown with maturity; stem equal, white, smooth; ring superior, large, white.

Distribution: grows in coniferous and broadleaved forest among moss (1800 m a.s.1.); solitary to scattered.

Chlorophyllum rachodes (Vittad.) Vellinga (App. 1/33); basidioma medium to large; cap spherical in early stage, convex, finally plane, reddish brown in the middle, breaks up as fibrillose-scales due to expansion of the cap, whitish outside, slightly depressed in the middle; gills free, close, whitish cream; stem equal, with clavate to subspherical bulb, white, discolouring reddish brownish on handling, smooth to slightly fibrillose; ring superior, whitish, thick, double, movable.

D i s tribution: grows among the grass, under trees and shrubs (800 $\mathrm{m}$ a.s.1.); in soil, solitary.

Chlorophyllum hortense (Murrill) Vellinga; basidioma small to medium, cap convex with distinctly umbo in the middle, white to cream-colored, covered with small patches of yellowish brown squamules; margin faintly straight; gills free, crowded, whitish, becoming dirty white, turn olive green on drying; stem subcylindrical, fibrillose, white to whitish, base not enlarged; ring persistent.

Distribution: grows among the grass and leaf litter, and under trees and shrubs, (1900 m a.s.l.); solitary to caespitose, in soil.

Cystolepiota seminuda (Lasch) Bon (App. 1/34); basidioma small; cap obtuse conic-campanulate, planoconvex to plane, with a flat disc in the middle, surface off whitish in the disc, with densely floccose velar remnants in the middle, expended outwards as milky white-powdered covering, margin appendiculate; gills free, white, crowded; stem equal, with slightly expanded base, fistulose at base, pale lemon yellow, covered with white-powdered to pruinose remnants; ring superior, whitish, detached on handling.

Distribution: grows among leaf litter and cow dung, solitary to caespitose.

Coprinus comatus (O. F. Müll.) Pers. (App. 1/35); basidioma small to medium, tall; cap conicocampanulate, covered with white, recurved scales; gills free, crowded, white, to pinkish brown, becoming black and inky; stem terate to slightly swollen at base, tall, white, smooth, sometimes fistulose; ring median, movable, disappears quickly.

Distribution: grows in lawns, at roadsides, in gardens and open areas, in Pine forests, in elevation range from 1800-2000 $\mathrm{m}$ a.s.l.; solitary to scattered.

Coprinus plicatilis (Curtis) Fr. (App. 1/36); basidioma tiny, small; cap campanulate, plano-convex with age, grayish brown, distinctly grooved as sulcatestriate, with a flat, yellowish brown disc; gills free, distant, grayish to blackish; stem terate, brittle, smooth, translucent. 
D i s tribution: grows in lawn, open areas, flowers pots, roadsides and garden, in elevation range from 600-1500 m a.s.1.; solitary to gregarious.

Cyathus stercoreus (Schw.) de Toni. (App. 1/37); basidioma tiny, nest-shaped, generally inverted conical in shape, outer surface blackish brown, to brownish, inner surface grayish black, periodioles flattened, dark grayish to black, egg-like.

Distribution: grows on dung, in soil containing dung and wood chips, in elevation range from 1800$2100 \mathrm{~m}$ a.s.1.; gregarious, scattered.

Lepiota clypeolaria (Bull. ex Fr.) P. Kumm. (App. 1/38); basidioma small to medium; cap convex to plano-convex, grayish pink, with a smooth reddish brown disc in the middle, breaks up into paler reddish brown fibrillose scales due to the cap expansion towards outside; gills free, close, whitish; stem equal, with slightly expanded base, whitish, surface orangish yellow, darker on handling; ring superior, whitish.

Distribution: grows in mixed woodland, among the grass, (800-1800 $\mathrm{m}$ a.s.1.); solitary to scattered.

Lepiota cristata (Fr.) Kummer (App. 1/39); basidioma small; cap campanulate, plano-convex, with a broad umbo in the middle, wine brown in the middle, whitish outwards, breaks up into wine brown fibrillose scales due to the cap expansion towards outside; gills free, close, creamish; stem equal, with slightly expanded base, whitish, smooth to slightly fibrillose; ring superior, whitish, disappears quickly.

Distribution: grows under trees, among moss, (2000 $\mathrm{m}$ a.s.1.); solitary or in cluster.

Leucocoprinus birnbaumii (Corda) Singer (App. 1/40); basidioma small; cap conic-campanulate to broad bell shaped, then plane, with a flat disc in the middle, surface lemon yellow, covered with lemon yellowish warts or scales, disc darker than cap, margin distinctly lined with dark and light lemon yellow colour; gills free, crowded, yellow; stem tapering upwards, with slightly expanded base, sometimes fistulose at base, pale lemon yellow, covered with finely yellowish-powdery remnants; ring superior, yellowish.

Distribution: grows in gardens, open areas, outskirts of forest, among leaf litter, in elevation range from 800-1800 m a.s.1.; solitary or in cluster.

Lycoperdon perlatum Pers.; basidioma small, pear shaped to subglobose with stem, whitish, brownish with age, covered with conical spines.

D is tribution: grows on the ground, in open land, in coniferous and oak forest, in elevation range from 1800-2300 m a.s.l.; solitary to scattered.

Macrolepiota procera (Scop.) Singer (App. 1/41); basidioma medium to large; cap convex to plano-convex with age, with flat umbo in the middle, white, often covered with light brown to brownish small squamules, split and scattered due to the development of fruit body, disc pale grayish brownish; gills free, remote, densely crowded, white; stem cylindrical with broadened base, covered with whitish to brownish squamules; ring superior, whitish, with a brownish dorsal side, movable on the stipe.

Distribution: grows in open pine woodland, among the grass, in elevation range from 1800-2300 m a.s.l.; solitary to scattered.

U se s: local people identify this mushroom on the basis of its white, large and stout fruitbody and eat.

Other species from the family Agaricaceae: Agaricus placomyces Peck; A. trisulphurcatus Ber. (App. 1/42); A. xanthodermus Genev.; Leucocoprinus birnbaumii (Corda) Singer; L. fragilissimus (Berk. \& M.A. Curtis) Pat.

Family: Psathyrellaceae

(Number of specimens: 5)

Coprinellus disseminates (Pers.) J. E. Lange; basidioma tiny, small; cap ovoid at first, broad campanulate with age, pale buff to brownish, grooved towards margin as sulcate-striate, with a flat disc, surface sometimes scurfy; gills adnate, subdistant, grayish then blackish; stem terete, fragile, pallid, smooth to fairly hairy. D i s tribution: grows in woody debris, in elevation range from 600-2100 $\mathrm{m}$ a.s.l.; gregarious or in large groups.

Other species from the family Psathyrellaceae: Coprinellus micaceus (Bull.) Vilgalys, Hopple \& Jacq. Johnson; Panaeolus semiovatus (Sowerby) S. Lundell \& Nannf.

Family: Strophariaceae

(Number of specimens: 16)

Gymnopilus spectabilis Hesler; basidioma medium; cap convex to applanate with an umbo in the middle, corn to light chrome, to golden yellowish, surface covered with thin fibrillose scales; gills adnate, golden yellowish, crowded, grayish brown; stem terete, slightly bulbous at the base, yellowish brown, covered with thin fibrillose-scales; ring superior, membranous.

Distribution: grows in wood stumps, in broadleaved and coniferous forest (2000 m a.s.l.).

Hypholoma fasciculare (Huds. ex Fr.) Kummer; basidioma small; cap convex plano-convex, then applanate, lemon yellow with ochre green hue, yellowish brown in the centre, smooth; gills adnexed, close to crowded, lemon yellowish, purplish brown with age due to spores; stem central, yellow to greenish yellow, brownish at the base.

Distribution: grows on fallen tree trunks, in coniferous forest and broadleaved forest, in dense cluster (800 m $1800 \mathrm{~m}$ a.s.1.).

Pholiota squamulosa (Murr.) Kauffman; basidioma small; cap convex to plano-convex, surface covered 
with thin squamules, orangish brown to tawny, sticky when wet; gills adnate, crowded, pale yellowish to brownish; stem tapering downwards, yellowish brown, fibrillose, ring superior, disappears quickly.

Distribution: grows in broadleaved forest, on dead wood, (2000 $\mathrm{m}$ a.s.1.), solitary or in cluster.

Stropharia rugosoannulata Farlow ex Murr. (App. 1/43); basidioma medium to large; cap convex to planoconvex, than flattened with uplifted and appendiculate margin, surface reddish brown to purplish red, pallid outwards, subviscid, margin crenate with wartyscale velar remnants; gills adnate, crowded, grayish, becoming black; stem tapering upwards, with slightly expanded base, whitish, base with white rhizomorphs; ring superior, white.

$\mathrm{D}$ is tribution: grows in forest open areas, on fallen decomposing leaves, elevation range from 1800-2200 m a.s.1.; solitary to scattered.

Other species from the family Strophariaceae: Pholiota squarrosa (Vahl) P. Kumm.; Gymnopilus zenkeri (Henn.) Singer; Cyclocybe aegerita (V. Brig.) Vizzini; Agrocybe badia (Petch) Pegler; Hebeloma vinosophyllum Hongo; Psilocybe coprophila (Bull.) P. Kumm.

Family: Boletaceae

(Number of specimens: 20)

Boletus edulis Bull. ex Fr.; basidioma medium to large, stout; cap convex, nearly plane with age, dark yellowish brown, viscid when wet, surface with wrinkles; hymenophore in the form of pores, small, yellowish green; stem stout, equal, clavate at the base, pale brown to brownish, often with white reticulation at the apex.

Distribution: grows in mixed forest, under Cedrus deodara and oak trees, elevation range from 2000-2200 m a.s.1.; solitary to scattered, sometimes caespitose.

Leccinum aurantiacum (Bull.) Gray; basidioma medium to large, stout; cap convex, nearly plane with age, reddish brown to dark orangish brown, surface with thin fibrils; hymenophore in the form of pores, small, pallid to yellowish green; stem stout, equal to clavate at the base, palid with wooly-fibrilose scales; flesh staining grayish to bluish at the base.

Distribution: grows in mixed forest, mostly with conifer trees, in elevation range from 1900-2200 m a.s.1.; solitary to scattered.

Phylloporus rhodoxanthus (Schw.) Bres.; basidioma medium; cap convex, than applanate with age, reddish brown, fibrillose tomentose; hymenophore in the form of gills, decurrent, subdistant, golden yellow, bruising blue; stem equal to tapering downwards, with longitudinal ridges at the apex, yellowish.
Distribution: grows in coniferous forests, under Cedrus deodara and Cupressus torulosa, in elevation range from 1900-2300 $\mathrm{m}$ a.s.l.; in soil, solitary to scattered.

Pulveroboletus auriflammeus (Berk. \& M.A. Curtis) Singer (App. 1/44); basidioma medium; cap convex, then applanate with age, dark yellow, surface floccose to felty; hymenophore adnexed, lemon yellow, in the form of pores, light yellowish, bruising brown; stem equal to tapering downwards, concolouros with the cap, surface pruinose overall.

D i s tribution: grows in oak forest, under Quercus leucotrichophora, in elevation range from 1900-2300 m a.s.l.; in soil, solitary to scattered.

Strobilomyces floccopus (Fr.) Karsten; basidioma medium to large; cap convex, then applanate with age, ash grey to blackish, surface with large fllocose-scaley warts, margin appears appendiculate due to scaly warts; hymenophore whitish, brick reddish on bruising; stem equal, concolouros with the cap, surface covered with large floocose-scaly warts; ring in the form of covering wooly scales.

D i s tribu ti on: grows in oak and coniferous forests, under oak, Cedrus deodara, and Cupressus torulosa trees, in elevation range from 1900-2300 m a.s.1.; solitary to scattered.

Strobilomyces mirandus Corner (App. 1/45); basidioma small to medium; cap convex, vivid yellow to sunflower yellow, surface densely squamulose with flat to bluntly pyramidal or wart-like squamules; margin wavy with cottony veiler remnant; pore surface covered by partial veil when young, smoky white; brownish initially then blackish on bruising; pore angular; tube adnate-sinuate, chalky to smoky white, then greyish brown; stem concolorous with pileus, with cotton-like annular region, surface with reticulations on the upper portion of annular region; tissues turning greyish orange and then brownish grey or brownish black on exposure. Distribution: grows under Quercus glauca Thunb. and Cinnamomum tamala, (2300 m a.s.1.); solitary to scattered.

Suillus brevipes (Pk.) Kuntze; basidioma medium to large, stout; cap convex, nearly plane with age, reddish brown, faded towards margin, surface viscid when wet; hymenophore in the form of pores, small, light wine brown; stem stout, equal, light yellowish.

Distribution: grows in conifer forest, under Cedrus deodara, in soil, in elevation range from 1900$2300 \mathrm{~m}$ a.s.l.; solitary to scattered.

Suillus pictus (Pk.) Smith \& Thiers (App. 1/46); basidioma medium to large; cap convex, then nearly flat with age, reddish brown, with brick red warty scales, margin appendiculate; hymenophore in the form of pores, light yellowish, brown on bruising; stem stout, equal, pinkish brown to wine brown at the apex, grayish brown at the base; ring superior, whitish, fibrous. 
Distribution: grows in coniferous forest, under Cedrus deodara, in soil, in elevation range from 1900$2300 \mathrm{~m}$ a.s.1.; solitary to scattered.

Other species from the family Boletaceae: Boletus erythropus (Fr.) Krombh.; Suillus cavipes (Opat.) A.H. Sm. \& Thiers; Pulveroboletus viridis Heinem. \& Gooss.-Font.; Strobilomyces strobilaceus (Scop.) Berk.; Boletellus russellii (Frost) E.-J.Gilbert

Family: Cortinariaceae

(Number of specimens: 8)

Cortinarius archeri Berk.; basidioma medium; cap convex to plano-convex, with a conic umbo in the middle, surface glutinous to viscid, purple, to purplish brown; gills adnexed, purplish brown; stem lilac at the apex, rusty brownish at cortina, purplish brown downwards, base covered with white rhizomorphs; ring in the form of cortina, rusty brown.

D is tribution: grows in broadleaved forest, among decomposing oak and Cinnamomum tamala leaves (2200 m a.s.1.); solitary.

Cortinarius purpurascens (Fr.) Fr; basidioma medium; cap convex to plano-convex, finally applanate, with a conic umbo in the middle, brownish with purple tinge; gills adnexed close, lamellulae of various length, purplish brown; stem terete with a slightly bulbous expanded base, light violaceous, tinge.

D i s tribution: grows in broadleaved forest, under oak trees, in elevation range from 1900-2200 m a.s.l.; in soil, solitary.

Other species from the family Cortinariaceae: Cortinarius bolaris (Pers.) Fr.

Family: Inocybaceae

(Number of specimens: 6)

Inocybe fastigiata (Schaeff. ex Fr.) Quél.; basidioma small; cap conical, then flat with an umbo, grayish yellow to yellow-ochre, with a distinct radial craks, coverd with small fibrils; gills adnexed close, creamish, then grayish yellow; stem terete, light grayish yellow. Distribution: grows in broadleaved \& mixed forest, under oak and Cedrus deodara trees, in elevation range from 1800-2200 $\mathrm{m}$ a.s.l.; in soil, solitary, scattered.

Other species from the family Inocybaceae: Inocybe violaceocaulis Matheny \& Bougher; I. relicina (Fr.) Quél.

Family: Entolomataceae

(Number of specimens: 9)

Entoloma lividoalbum (Kühner\& Romagn.) Kubička; basidioma small to medium; cap convex to applanate with age, yellowish brown to brown, with innate fibrils, surface translucent-striate; gills adnate, lamellulae of various lengths, close, light pinkish; stem terete, whitish, faintly covered with thin fibrillls.

Distribution: grows in broadleaved forest, under the canopy of oaks, among the grass, in elevation range from 1800-2200 m a.s.1.; solitary to scattered.

Entoloma serrulatum (Fr.) Hesler; basidioma small; cap convex to applanate with age, purplish to purplish brown, with faintly striate margin; gills adnate, close, bluish grey; stem terete, bluish grey, smooth.

D i s tribution: grows in broadleaved forest, among the grass, in elevation range from 1900-2200 m a.s.l.; solitary to scattered.

Other species from the family Entolomataceae: Entoloma vernum S. Lundell; E. vulsum E. Horak; Clitopilus prunulus (Scop.) P. Kumm.

Family: Gomphaceae (Number of specimens: 5)

Gomphus floccosus (Schwein.) Singer (App. 1/47); basidioma medium to large; cap funnel-shaped, orange to orangish yellow, in the middle, darker outwards as orangish red, surface with viscid scales, margin wavy, uplifted; hymenophore consisting of veins or wrinkled, deep decurrent, orangish yellow pale cream; stem stout, tapering downwards, color similar to hymenophore, smooth.

Distribution: grows in broadleaved, mixed and coniferous forest, under oak, and Cedrus deodara trees, in soil, in elevation range from 1900-2200 m a.s.l.; solitary to scattered.

Ramaria aurea (Schaeff.) Quél. (App. 1/48); basidioma robust, branched, bright yellowish to yellowish orange, terminal branches lemon yellowish; stem short, thick with many branches, branches repeatedly dichotomous, rhizomorph whitish.

$\mathrm{D}$ is tribution: grows in mixed forest, under pine, and oak, in elevation range from 1900-2200 $\mathrm{m}$ a.s.l.

$\mathrm{U}$ s e s: very common to eat by local villagers in the Garhwal region.

Ramaria botrytis (Pers.) Ricken; basidioma robust, branched, bright pinkish orange, terminal branches fading to pale yellowish; stem short, thick with many branches, branches repeatedly dichotomous, rhizomorph whitish.

D i s tribution: grows in mixed forest, in soil, under pine, Cedrus deodara, and oak trees, in elevation range from 1900-2200 $\mathrm{m}$ a.s.1.

$\mathrm{U}$ s e s: very commonly eaten by local villagers in the Garhwal region.

Ramaria stricta (Fr.) Quél.; basidioma robust, branched, orangish to pinkish buff, terminal branches creamish yellow; stem short, thick with many branches. D is tribution: grows in coniferous and broadleaved forest, on unidentified dead wooddebris under Cedrus 
deodara, Cupressus torulosa and oak trees, in elevation range from 1900-2200 $\mathrm{m}$ a.s.1.

Family: Tricholomataceae

(Number of specimens: 23)

Clitocybe gibba (Pers.) P. Kumm. (App. 1/49); basidioma small to medium; cap infundibuliformis, with wavy and uplifted margin, grayish pink to grayish yellow; gills decurrent, grayish yellow, crowded, often forked; stem terete, concolorous with the cap, smooth.

Distribution: grows in coniferous and broadleaved forest, in soil, under oak, Shorea robusta, and Cedrus deodara trees, in elevation range from 1900-2300 m a.s.1.; gregarious to scattered.

Collybia butyracea (Bull.) P. Kumm. (App. 1/50); basidioma medium; cap broadly convex with a broad low umbo in the middle, wine brown to reddish brown, viscid when wet; gills adnexed, crowded, whitish to palid, lamellulae of various length; stem tapering downwards, whitish, sometimes covered with whitish zigzag fibrils.

Distribution: grows in coniferous forest, under Cedrus deodara, in elevation range from 1900-2200 m a.s.l.; in soil, scattered to gregarious.

Collybia dryophilla (Bull. ex Fr.) P. Kumm.; basidioma medium; cap convex, finally applanate, ochre brown to tan; gills adnexed, crowded, whitish; stem terete, light reddish brown, smooth.

Distribution: grows in coniferous forest, under Cedrus deodara, in elevation range from 1900-2200 m a.s.l.; in soil, scattered to gregarious.

Lepista nuda (Bull. ex Fr.) Cooke; basidioma small to medium; cap convex than applanate with depressed centre, margin often wavy, uplifted, bluish purple, fading away with age to grayish brown; gills adnexed, crowded, often forked, lilac, tan with age; stem terete, concolorous with the cap.

D i stribution: grows in coniferous and broadleaved forest open areas, under Cedrus deodara, pine and oak trees, among the grass, in soil, sometimes near to planted lemon trees, in elevation range from 1800-2200 m a.s.l.; gregarious or caespitose.

Termitomyces eurrhizus (Berk.) R. Heim; basidioma medium to large; cap conico-campanulate, then plane, with large umbo in the middle, light brownish to grayish brown, tuberculate to bumpy surface; gills free, white, crowded, edges serrate; stem cylindrical with clavate downwards, pseudorrhiza long, grayish white to dirty white.

Distribution: fairly common, grows in soil on ant mounds, in mixed dipterocarp forests under the canopy of Shorea robusta and Pinus roxburghii in the Shiwalik Range Hiamalaya, solitary.
U s e s: collected and eaten by local people of lower Shiwalik region, in elevation range from 600-800 m a.s.1.

Termitomyces heimii Natarajan; basidioma medium to large; cap plano-convex with a distinct conic umbo in the middle, whitish, umbo darker - grayish brown, surface wrinkled; gills adnexed, crowded, white, then pinkish, stem tapering downwards, whitish, pseudorrhiza long; ring superior.

Distribution: grows in soil, on ant mounds, often under the canopy of Shorea robusta and Pinus roxburghii, in elevation range from $600-800 \mathrm{~m}$ a.s.l.; solitary.

U s e s : collected and eaten by local villagers in lower Shiwalik region.

Termitomyces microcarpus (Berk. \& Broome) R. Heim (App. 1/51); basidioma tiny to small; cap first campanulate than applanate, often with a small umbo in the middle, grayish orange, radial streaks towards the margin; gills free, close; stem terete, cream white.

D i s tributi o n: very common in dipterocarp forest, dominated by Shorea robusta and Tectona grandis, near termite mounds, in the lower Shiwalik Hills of Garhwal Himalaya, in elevation range from $600-800 \mathrm{~m}$ a.s.l.; gregarious to scattered.

U s e s : people in the villages of lower Shiwalik region eat this mushroom.

Tricholoma saponaceum (Fr.) Kummer (App. 1/52); Grows in coniferous and broadleaved forests, solitary to gregarious; basidioma small to medium; cap convex, then plane, often with a sub-conic umbo in the middle, smooth, olivaceous grey to olive brown, dark in the middle, surface cracked on maturity; gills adnexed, subdistant, whitish, lamelluale of various length; stem equal to tapering downwards, whitish.

D is tribution: grows in coniferous and broadleaved forests, under oak and pine trees, in elevation range from 600-900 m a.s.1.; solitary to gregarious.

Tricholomopsis rutilans (Schaeff.) Singer (App. 1/53); basidioma medium; cap convex, then plane, pinkish grey, densely covered with dark pinkish red to reddish brown tufts or warts; gills adnate, close, pinkish grey, lamelluale of various length; stem equal, concolourus with the cap, with white rhizomorphs at the base, whitish.

D i s tribution: grows in broadleaved forests, often under the trees of oak, in elevation range from 1800$2000 \mathrm{~m}$ a.s.l.; solitary to gregarious.

Other species from the family Tricholomataceae: Tricholoma virgatum (Fr.) P. Kumm. (App. 1/54), Lepista sordida (Sowerby) Pat., Clitocybe geotropa (Bull.) Fr., Clitocybe dealbata (Sowerby) Gillet, Collybia fusipes (Bull.) Quél, Omphalina pyxidata (Bull.) Quél. and Clitocybe trogioides Corner. 
Family: Hydnangiaceae

(Number of specimens: 7)

Laccaria amethystina (Bull. ex Mérat) Murr.; basidioma small to medium; cap convex, planoconvex, finally applanate with wavy margin, deep purplish, quickly changing to pale purplish grey, even more fading with age, surface rough, radially striate throughout; gills adnexed,purplish, distant; stem terete, concolorous with the cap.

Distribution: grows in coniferous and broadleaved forest, often under Cedrus deodara and oak trees, in elevation range from 1900-2200 m a.s.1.; gregarious.

Laccaria laccata (Scop. ex Fr.) Cooke (App. 1/55); basidioma small to medium; cap convex, plano-convex, finally applanate with wavy and uplifted margin, centre often depressed, grayish brown, tawny, faded towards margin, radially striate throughout; gills adnexed,grayish brown, distant; stem terete, concolorous with the cap, twisted.

Distribution: grows in coniferous and broadleaved forest, in open grassy area, in elevation range from 1900-2200 m a.s.1.; gregarious to scattered.

Other species from the family Hydnangiaceae: Laccaria bicolor (Maire) P.D. Orton; L. lateritia Malençon.

Family: Cantharellaceae

(Number of specimens: 10)

Cantharellus cibarius Fr. (App. 1/56); basidioma small to medium; cap shallowly convex, then plane, disc shallowly depressed, yellow, lemon yellow to deep yellow with age, glabrous to minutely tomentose; hymenophore without true gills, reduced to ridges, subdecurrent, subdistant, forked, sometimes intervened at the margin, concolorous with the cap; stem compressed, concolorous with the cap.

Dis tribution: grows in coniferous, mixed and broadleaf forests but primarily grows under Cedrus, Pinus, Quercus, Rhododendron and Myrica, in open areas, among the grass, even moss, in elevation range from 1900-2300 $\mathrm{m}$ a.s.1.; gregarious to scattered.

U ses: one of the common species to eat in the Garhwal region. However, in some places researchers encouraged local people to eat Cantharellus cibarius.

Cantharellus minor Peck; basidioma small to very small; cap convex with recurved or enrolled margin, then flat with a depressed center, appearing funnel-shaped, yellow to pale yellow, smooth; hymenophoredecurrent, bifurcate, yellowish; stipe terete, concolorous with the cap, smooth.
D is tribution: grows in coniferous and broadleaved forests, under Cedrus deodara and oak trees, in open areas, among the grass, in elevation range from 1900$2200 \mathrm{~m}$ a.s.1.; gregarious to scattered.

U s e s: not as commonly eaten as Cantharellus cibarius, but in some places this species is also collected and consumed.

Craterellus cornucopioides (L. ex Fr.) Pers.; basidioma small to medium; cap funnel-shaped to tubular, margin flared, wavy, split, blackish brown, covered with blackish scales; hymenophore smooth, wrinkled with age, ash gray; stipe ash gray to grayish.

D i s tribution: grows in broadleaved forests, under Cinnamomum tamala and oak trees, in soil, among leaf litter, in elevation range from 1900-2300 m a.s.1.; gregarious to scattered.

Other species from the family Cantharellaceae: Cantharellus appalachiensis R.H. Petersen; C. friesii Quél; C. infundibuliformis (Scop.) Fr.

Family: Polyporaceae

(Number of specimens: 5)

Fomes fomentarius (L. ex Fr.) Kickx.; basidioma hoof-shaped, grayish brown to grayish black, often with concentric zones, surface faintly velvety; hymenophore in the form of pores, brownish.

D i s tributi on: grows on dead or living tree trunks of Juglans regia, Delonix regia (Bojer) Raf. and many other unidentified tree trunks with various elevation ranges.

Polyporus arcularius (Batsch) Fr. (App. 1/57); basidioma plane with deep depression in the middle, grayish orange, with grayish brown scales, often cracked due to expansion of the cap; tubes decurrent, creamish then light brown, angular; stem small, grayish brown, later reddish brown.

Distribution: grows on living wood trunks, in moist conditions, on trunk surface covered with moss; $2200 \mathrm{~m}$ a.s.l.; scattered to gregarious.

Other species from the family Polyporaceae: Lentinus tigrinus (Bull.) Fr.; Polyporus alveolaris (DC.) Bondartsev \& Singer.

Family: Pleurotaceae

(Number of specimens: 2)

Pleurotus cornucopiae (Paulet) Rolland; basidioma small; cap fan-shaped, applanate, whitish with light pinkish hue, glabrous to thin velvety in the center; gills decurrent, whitish; stem lateral, concolorous with the cap.

D istribution: grows on dead wood, especially Euphorbia sp., tree trunks, solitary (800 m a.s.1.). 
Us es : this species is commonly eaten in the lower valleys of Garhwal Himalaya.

Pleurotus ostreatus (Jacq.) P. Kumm.; basidioma medium to large; cap shell or fan shaped, grayish brown to creamish, margin wavy; gills decurrent, crowded, creamish; stem eccentric to lateral, small, creamish.

D i s tribution: grows on dead wood, or living tree trunks of Juglans regia and Cedrus deodara, caespitose to solitary, with various elevation ranges.

U s e s : people in some places of Garhwal Himalaya collect and eat this mushroom.

Family: Pluteaceae

(Number of specimens: 4)

Pluteus plautus (Weinmann) Gillet; basidioma small; cap convex then expanded at maturity, centre slightly depressed, light brown in the middle, dirty white outwards, margin striate; gills free, moderately crowded, buff; stem cylindrical, creamish white.

$\mathrm{D}$ is tributio n: grows on tree trunks in broadleaved forests, on oak trees (2000 m a.s.1.); solitary.

Other species from the family Pluteaceae: Volvariella bombycina (Schaeff.) Singer; $V$. volvacea (Bul.) Singer.

Family: Marasmiaceae

(Number of specimens: 7)

Marasmius oreades (Bolton ex Fr.) Fr. (App. 1/58); basidioma small; cap convex with a small umbo in the middle, grayish brown to buff brown, creamish white with age, margin striate; gills adnexed, subdistant, creamish; stem equal, tough, concolorous with the cap. Distribution: grows in broadleaved and coniferous forests, among leaf litter, gregarious.

Marasmius rotula (Scop. ex Fr.) Fr.; basidioma small; cap convex, with depressed centre, distinct radial grooves overall, yellowish brown, darker in the middle; gills adnexed, distant, creamish; stem equal, yellowish white, reddish brown downwards.

Distribution: grows in coniferous forest, on leaf litter, under pine and Cedrus deodara trees, in elevation range from 1800-2100 $\mathrm{m}$ a.s.l.; scattered.

Family: Mycenaceae

(Number of specimens: 7)

Mycena galopus (Pers.) P. Kumm.; basidioma tiny; cap campanulate, grayish brown margin radially lined overall; gills adnate, distant, creamish white; stem equal, grayish brown.

Distribution: grows on leaf litter and woody debris in broadleaved and coniferous forests, in elevation range from 1900-2200 $\mathrm{m}$ a.s.1.
Family: Physalacriaceae

(Number of specimens: 7)

Armillaria gallica Marmx. \& Romagn.; basidioma medium to large; cap convex to plano-convex, with incurved margin, often with depressed centre, yellowish to golden yellow, honey yellow in the middle when wet, covered with darker squamules in the middle; gills decurrent, grayish yellow to yellowish; stem terete, creamish at apex, yolk yellow below ring, often covered with small floccose scales; ring superior, yellowish.

Distribution: grows on living and dead tree trunks, generally at the bottom of a tree, mostly on Cedrus deodara (2000 m a.s.1.); gregarious or in cluster.

Oudemansiella mucida (Schrad.) Höhn. (App. 1/59); basidioma medium; cap convex, plano-convex, finally applanate grayish brown, whitish with age, surface wrinkled, viscid when wet, margin faintly striate; gills adnexed, notched, close, creamish white; stem equal, reddish brown; ring whitish.

Distribution: grows on living tree trunks, in broadleaved forest, on oak trees, among moss (2000 m a.s.1.); solitary to caespitose.

Xerula radicata (Relhn) Dörfelt (App. 1/60); basidioma large; cap convex, plano-convex, finally applanate, grayish brown, often with brown fibrils; gills adnexed,white, distant; stem tapering upwards, with deep, long root base, brownish fibrillosy towards the base.

D is tribution: grows in coniferous and broadleaved forest, under Cedrus deodara and oak trees, deep rooted, attached with buried wood, in elevation range from 2000-2200 m a.s.1.; solitary.

Family: Lyophyllaceae

(Number of specimens: 2)

Asterophora lycoperdoides (Bull. ex Mérat) Gray (App. 1/61); basidioma small; cap globose to subglobose, then convex, distinctly covered with claybuff mealy coating, surface off-whitish in colour; gills adnate, whitish, translucent, close; stem whitish.

D i stribution: grows on other fungi, especially on Russula nigricans, in elevation range from 1900-2300 m a.s.1.; caespitose.

Lyophyllum turcicum Sesli, Vizzini \& Contu.; basidioma medium; cap broadly convex to applanate, depressed or umbilicate in the middle, grayish yellow to grayish orange with dark brown centre, smooth; gills close, adnate but easily separable from the stipe junction, white; stem equal but with the broadened base, whitish.

D i s tribution: grows in clusters, caespitose, under Quercus leucotrichophora, at elevation 2280 m a.s.1. 
Family: Auriculariaceae

(Number of specimens: 2)

Auricularia auricula-judae (Bull.) Quél.; basidioma small, irregularly fan-shaped, upper surface soft and fluffy, light brown to wine brown, lower surface smooth to hairy in the middle, wrinkled, pale brownish, gelatinous; stem sessile or sometimes attached to the substrate by a short stalk.

D i s tribution: grows on dead or living tree trunks, especially on Grievillea robusta A. Cunn. ex R. Br., Delonix regia, Bauhinia malabarica and oak trees, at various elevation ranges.

Us es : This species is eaten by the Tibetan refugees, who consume it both fresh and dried. Dried fruiting bodies are revived with water and then fried with onions. In Tibetan language it is known as "Muro". Local people are not aware of edibility of this mushroom (Semwal et al., 2014).

Auricularia polytricha (Mont.) Sacc.; basidioma small, irregularly fan-shaped, brownish to dark brown, upper surface glutinous, dorsal side grayish black, hairy; stem sessile or sometimes attached to the substrate by a short stalk.

Distribution: grows on dead and living wood, at various elevation ranges, solitary to gregarious, sometimes caespitose. The habitat is very similar to that of A. auricula-judae.

U s e s : this 'wood ear' mushroom is also eaten by the Tibetan people only (Semwal et al., 2014).

Family: Ganodermataceae

(Number of specimens: 1)

Ganoderma lucidum (Fr.) Karst.; basidioma medium to large; cap fan shaped to kidney shaped, reddish brown with zones of yellowish and white colours outwards; hymenophore in the form of small pores, whitish; stipe cylindrical, glossy, smooth, dark reddish brown.

D i s tribution: grows on oak tree trunks, at various elevation ranges, solitary or in clusters.

\section{Family: Sparassidaceae \\ (Number of specimens: 1)}

Sparassis crispa (Wulfen) Fr. (App. 1/62); basidioma medium to large; cap made up of curly and folded fronds, giving appearance of lettuce leaf or cauliflower, cream to cream-yellow to egg yellow with age; stipe thick, stout, short and yellowish white.

Dis tribution: grows at the base of tree trunks of Cedrus deodara, in elevation range from 1900-2200 m a.s.1.

U s e s : local people love to eat this mushroom due to its good taste.

\author{
Family: Geastraceae \\ (Number of specimens: 1)
}

Geastrum saccatum Fr. (App. 1/63); basidioma bulbous, splits and bends back into 4-6 lobs, appears as star-shaped, grayish yellow to buff, spore sac round, with disc-like opening.

Distribution: grows on decaying leaf litter, in broadleaved forest, under oak and Myrica esculenta trees, in elevation range from 1900-2300 m a.s.1.; solitary or in groups.

\section{Family: Phallaceae \\ (Number of specimens: 1)}

Mutinus caninus (Pers.) Fr. (App. 1/64); basidioma small, egg shpaped in initial stage, later emerges as cylindrical stem, with conical apex, with small opening, stem pinkish gray, apical part covered with orangish brownish slime, having unpleasant smell, which soon liquefies.

D i s tribution: grows among leaf litter, outskirts of forest, in ground, in elevation range from 1700-2000 m a.s.l.; solitary to gregarious.

\section{Family: Clavariaceae (Number of specimens: 1)}

Clavaria fragilis Holmsk. (=C. vermicularis Sw.) (App. 1/65); basidioma tall, thin-cylindrical, white, yellowish towards apex, sometimes forked.

D istribution: grows among the grass and moss, in coniferous forest with the canopy of Cedrus deodara and Cupressus torulosa, in elevation range from 1900$2300 \mathrm{~m}$ a.s.1.; in clusters or gregarious.

Family: Hydnaceae

(Number of specimens: 1)

Hydnum repandum (L. ex Fr.) Gray (App. 1/66); basidioma small; cap convex, then applanate, depressed in the middle, buff-orange, hymenophore in the form of teeth or spines, dull orangish; stipe central to eccentric, terete, concolorous with the cap.

Distribution: grows on ground, in coniferous forest, under Cedrus deodara and Cupressus torulosa, in elevation range from 1900-2200 m a.s.1.; scattered to gregarious.

Family: Diplocystaceae

(Number of specimens: 1)

Astraeus hygrometricus (Pers.) Morgan; basidioma small, globose to subglobose, on maturity outer peridium ruptures to form triangular-shaped lobes, exposing the inner peridium with a conspicuous ostiole. 
Distribution: grows on ground in soil, always associated with Shorea robusta and Tectona grandis trees, solitary, scattered.

U s e s : frequently used as food in the lower Shiwalik Hills (600 m a.s.1.) by local populace. During rainy season, people go to forest alone or in groups for mushroom forays and also sell them in the local market (Semwal et al. 2014).

Family: Dacrymycetaceae

(Number of specimens: 1)

Dacrymyces spathularia (Schwein.) G. W. Martin; basidioma spathula-shaped, bright yellow, margin wavy, surface glabrous.

Distribution: grows on fallen tree clumps, in mixed forests, in elevation range from 1900-2300 m a.s.1.; in clusters or in groups.

Family: Hericiaceae

(Number of specimens: 1)

Hericium erinaceus (Bull.) Pers.; basidioma stout, forming the cluster of rounded, elongated and pointed spines, white to yellowish, arises from a short, stout rooted stalk.

Distribution: grows on living tree stems, most of the times grows in cracks or on fallen wood stumps, at elevation range from 1900-2300 m a.s.1.; solitary. U s es: few people collect and eat this mushroom in the Garhwal Himalaya.

Family: Sclerodermataceae

(Number of specimens: 2)

Scleroderma cepa (Vaill.) Pers.; basidioma subglobose, often without stem, surface grayish brown to leather brown, smooth, soon cracked, inside white at first, choco-brown soon.

Distribution: grows on ground in conifer and broadleaved forest, under Cedrus deodara and Cupressus torulosa and oak trees, in elevation range from 1800-2300 m a.s.1.; solitary, scattered.

Family: Schizophyllaceae

(Number of specimens: 1)

Schizophyllum communae Fr. (App. 1/67); basidioma distinctly fan-shaped with wavy or lobed margin, orangish brown to grayish brown, later whitish, surface hairy; hymenophore with thick gills, distant, grayish orange to grayish; stem absent. In rainy season, a fruit body reaches its optimal size, while in other seasons, it is smaller or tiny.

D i s tribution: grows on dead and living tree trunks or on decomposing logs, round the year, at various elevation ranges; grows in clusters or scattered.

\subsection{Comments on the list of species}

Out of 323 specimens collected, 310 were identified and further grouped into 33 families, 75 genera and 198 species under Basidiomycota, while 13 specimens were grouped in 7 families, 7 genera and 11 species under Ascomycota. 127 species were observed in oak dominated temperate broadleaved forest, while 42 were found in coniferous forests and 19 in the mixed woodlands composed mainly of oak, Myrica, Rhododendron and pine trees growing in middle to higher hills, while in lower hills - dominated by Shorea robusta and Tectona grandis in dipterocarp forest. In terms of fungal species distribution, Amanitaceae, Russulaceae, and Boletaceae were found to be the most dominant in the oak dominated forest, Tricholomataceae and Cantharellaceae in pine and Cedrus dominated forests, Cortinariaceae in mixed forest, while Agaricaceae, Amanitaceae and Tricholomataceae were found dominant in dipterocarp forest of the lower Himalaya. The highest total number of species including all families was found near low to mid altitudes and it may be due to overlapping of different climatic conditions.

The highest number of specimens was recorded for the Basidiomycota families: Russulaceae (56), Amanitaceae (43) and Agaricaceae (41). The detailed data on the number of species representing individual families reported from the study area were presented in Figure 2. The most numerous species are represented in three genera: Russula (35), Amanita (20) and Lactarius (15).

The members of seven families, i.e., Russulaceae, Amanitaceae, Tricholomataceae, Boletaceae, Cantharellaceae, Cortinariaceae and Gomphaceae were found as main ectomycorrhizal forming species at the elevation range of 500-2800 m a.s.l. in all four forest types.

Among collected 323 wild mushrooms most significant edible species were: Amanita chepangiana, A. hemibapha, Astraeus hygrometricus, Auricularia spp., Cantharellus spp., Lactarius camphoratus (App. 1/68), Macrolepiota procera, Morchella spp., Pleurotus ostreatus, Ramaria spp., Sparassis crispa, and Termitomyces spp. The knowledge on edibility of some wild mushrooms, like Cantharellus cibarius, has been passed to local people by researchers, whereas the knowledge on edibility of some of wild species was already known by local inhabitants (Semwal et al. 2014). However, the species eaten by local people in the study area have already been described in the European or American mushroom field guides as edible mushrooms. Thus, the question arises - how 
local peoples got the knowledge on edibility of those wild mushrooms? It is an anthropogenic question and belongs to human tribe evolution within its natural resources. We also collected several medicinal mushrooms i.e., Ganoderma lucidum, Hydnum rependum, Schizophyllum communae, Ophiocordyceps nutans, and Fomes fomentarius, but there is no available record about the uses of wild mushrooms as a medicine by the locals. The Uttarakhand state is bestowed with a high percentage of forest area covered with various types of woody plant communities throughout the different altitudinal gradients and wild mushrooms play a vital role in the degradation of fallen leaf litter and wood logs and maintainance of a proper living forest ecosystems. There is a need to investigate the impact of wild mushrooms on the forest health in the Uttarakhand Himalaya, because many pathogenic and decomposer mushrooms were also collected in the present study that have been already described above as edible and medicinal mushrooms. However, most significant decomposer species found were: Armillaria gallica, Auricularia spp., Xylaria hypoxylon, Pleurotus ostreatus, Polyporus arcularis and Fomes fomentarius.

During the present investigation, we have seen several reports in local newspapers about mushroom poisoning from the remote villeage areas of the state of Uttarakhand. However, we could not manage to get there to collect the first hand information due to bad weather and heavy monsoon rain. Still, we managed to collect several poisonous wild mushrooms, i.e., Amanita oberwinklerana, Amanita subglobosa, Hygrocybe conica, and Hypholoma fasciculare.

\section{Conclusion}

The investigation revealed a huge treasure of wild mushrooms from the Uttarakhand Himalaya.There is a big scope to find out new species of wild edible and medicinal fungi which can be further investigated for new drug discovery, medicinal uses, and edible purposes. Furthermore, this study will serve as a baseline database of wild mushrooms for the state of Uttarakhand.

Acknowledgements. Authors are thankful to the Uttarkhand State Council for Science \& Technology (UCoST), Dehradun for financial support for the project (UCS\&T/R\&D/LS-1/1213/4912) namely "Collection, identification, documentation of wild edible and medicinal Mushrooms of Garhwal Himalaya of Uttarakhand". Thanks also given to several peoples who have helped us during forest forays in different forest areas in the study area.

\section{Author Contributions}

Research concept and design: K. C. Semwal \& V. K. Bhatt Acquisition and/or assembly of data: K. C. Semwal Data analysis and interpretation: K. C. Semwal Drafting the article: K. C. Semwal \& V. K. Bhatt Critical revision: K. C. Semwal

Final approval: K. C. Semwal

\section{References}

Bhatt R. P., Tulloss R. E., Semwal K. C., Bhatt V. K., Moncalvo J. M. \& Stephenson S. L. 2003. Amanitaceae reported from India. A critically annotated checklist. Mycotaxon 88: 249-270.

Binion D. E., Stephenson S. L., Roody W. C., Burdsall H. H., Vasilyeva L. N. \& Miller O. K. 2008. Macrofungi Associated with Oaks of Eastern North America. West Virginia University Press, Morgantown.

Bisht A. S. \& Bhatт A. B. 2013. Vegetational structure and plant diversity relation in a sub-alpine region of Garhwal Himalaya, Uttarakhand India. African Journal of Plant Science 7(8): 401-406.

Das K., Miller S. L. \& Sharma J. R. 2006a. Russula in Himalaya 2: Four new taxa. Mycotaxon 95: 205-215.

Das K. \& Sharma J. R. 2001a. A new record of Lactarius from India. Annals of Forestry 9: 284-286.

DAs K. \& Sharma J. R. 2001b. Russula rhodomelanea Sarnari - a new record for India. Mushroom Research 10: 109-111.
Das K. \& Sharma J. R. 2002. The genus Lactarius in India. Bulletin Botanical Survey of India 44: 75-88.

Das K. \& Sharma J. R. 2003. New records of Russula from Kumaon Himalaya. Indian Journal of Forestry 26: 320-326.

Das K. \& Sharma J. R. 2004. Lactarius in Kumaon Himalaya 2. New and interesting species of subgenus Plinthogali. Mycotaxon 89: 289-296.

Das K. \& Sharma J. R. 2005. New records of Lactarius from India. Annals of Forestry 13: 1-8.

Das K., Sharma J. R. \& Atri N. S. 2006b. Russula in Himalaya 3: A new species of subgenus Ingatula. Mycotaxon 95: 271-275.

Das K., Sharma J. R., Basso M. T. \& Bhatt R. P. 2005. Lactarius in Kumaon Himalaya 4: A new species of subgenus Piperites. Mycotaxon 91: 1-7.

Das K., Sharma J. R. \& Bhatt R. P. 2002. Russula flavida Frost - an addition to the Indian ectomycorrhizic fungi. Mushroom Research 11: 9-10. 
Das K., Sharma J. R. \& Montoya L. 2004a. Lactarius in Kumaon Himalaya 1. New species of subgenus Russularia. Fungal Diversity 16: 23-33.

Das K., Sharma J. R. \& Montoya L. 2004b. Lactarius in Kumaon Himalaya 3. A new species of subgenus Lactifluus. Mycotaxon 90: 285-290.

Das K., Sharma J. R. \& Verbeken A. 2003. New species of Lactarius from Kumaon Himalaya, India. Mycotaxon 88: 333-342.

Else H. \& Hvass H. 1978. Mushrooms and Toadstools. Blandford Press, London.

FSI 2003. Forest survey of India. The state of forest report, Dehradun, FSI, Ministry of environment and forests, Govt of India, New Delhi, pp.134.

Lamaison J. L. \& Polese J. M. 2005. The great Encyclopedia of Mushrooms. Konemann Tandem Verlag Gmbh.

Negi G. C. S. \& Dhyani P. P. 2012. Glimpses of forestry research in the Indian Himalayan region. $190 \mathrm{pp}$. Published by: G.B. Pant Institute of Himalayan Environment and Development, Almora \& M/s Bishen Singh Mahendra Pal Singh, India.

Phillips R. 2010. Mushrooms and Other Fungi of North America. Firefly Books Ltd. New York.

Semwal K. C. 2003. Systematics and Ecological Studies on the Genus Amanita from Garhwal Himalaya. Ph.D. thesis, H.N.B. Garhwal University (A Central University). Srinagar Garhwal, Uttarakhand, India.

Semwal K. C., Stephenson S. L., Bhatt V. K. \& Bhatt R. P. 2014. Edible Mushrooms of the Northwestern Himalaya, India: a Study of Indigenous Knowledge,
Distribution and Diversity. Mycosphere 5(3): 440-461. Doi 10.5943/mycosphere/5/3/7.

Semwal K. C., Tulloss R. E., Bhatt R. P., Stephenson S. L. \& UpADHYAY R. C. 2007. New records of Amanita section Amanita from Garhwal Himalaya, India. Mycotaxon 101: 331-348.

Semwal K.C., Bhatt R. P. \& Upadhyay R. C. 2005. The Genus Amanita from Garhwal Himalaya region of India. Mushroom Research 14(2): 50-55.

Semwal K.C., Bhatt R. P. \& Upadhyay R. C. 2006. Occurrence and growth characters of Amanita spp. in Garhwal Himalaya. Indian Phytopath 59(3): 309-313.

Semwal K. C., Bhatt V. K. \& Stephenson S. L. 2018, A survey of macrofungal diversity in the Bharsar region, Uttarakhand Himalaya, India. Journal of Asia - Pacific Biodiversity Vol. 11: 560-565. https://doi. org/10.1016/j.japb.2018.09.006

Sharma C. M. \& Kumar A. 1991. Community structure of some natural forest stands in Lansdowne forest range of Garhwal Himalaya. Journal of Tropical Forest Science 5(1): 8 -12.

Singer R. 1986. Agaricales in Modern Taxonomy. 4th eds. 981 pp. Bishan Singh Mahendra Pal Singh, Dehradun, India.

Suyal S., Sharma C. M., Sumeet G., Ghildiyal S. K., Rana C. S. \& Butola D. S. 2010. Phytodiversity (Angiosperms and Gymnosperms) in Chaurangikhal forest of Garhwal Himalaya, Uttarakhand, India. Indian Journal of Science and Technology 3(3): 267-275. 
Appendix 1. Macrofungal diversity in the Garhwal Himalaya, Uttarakhand, India

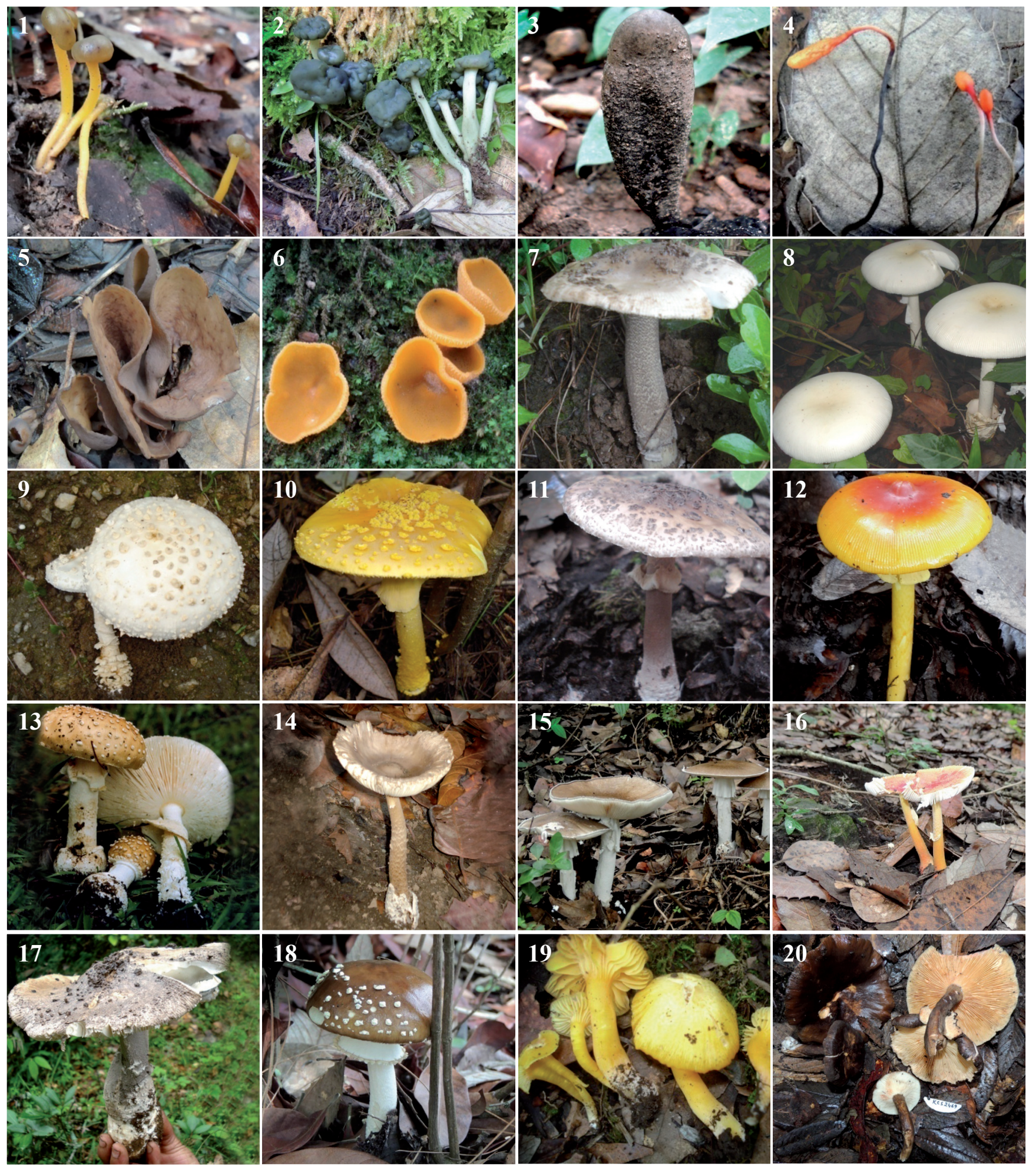

Explanations: 1. Leotia lubrica, 2. Leotia cf. viscosa, 3. Xylaria polymorpha, 4. Ophiocordyceps nutans, 5. Pezziza badia, 6. Aleuria aurantia, 7. Amanita ceciliae, 8. Amanita chepangiana, 9. Amanita concentrica, 10. Amanita flavipes, 11. Amanita fritillaria, 12. Amanita hemibapha, 13. Amanita orientigemmata, 14. Amanita ovalispora, 15. Amanita pseudoporphyria, 16. Amanita rubrovolvata, 17. Amanita sinensis, 18. Amanita subglobosa, 19. Hygrocybe chlorophana, 20. Lactarius fuliginosus, 21. Lactarius subindigo, 22. Lactarius zonarius var. riparius, 23. Lactifluus piperatus, 24. Russula amoenolens, 25. Russula atropurpurea, 26. Russula brevipes, 27. Russula flavida, 28. Russula foetens, 

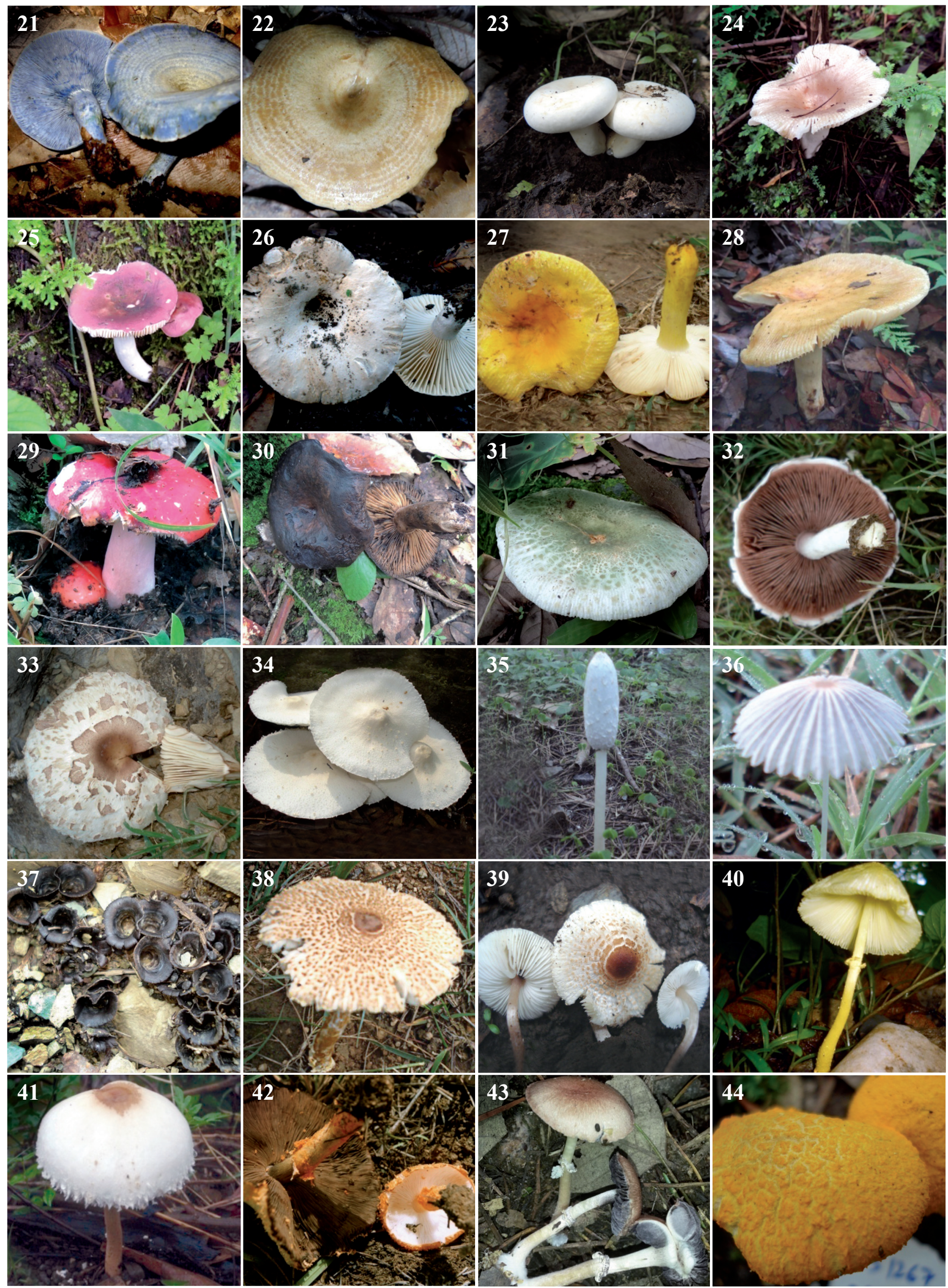

29. Russula lepida, 30. Russula nigricans, 31. Russula virescens, 32. Agaricus campestris, 33. Chlorophyllum rachodes, 34. Cystolepiota seminuda, 35. Coprinus comatus, 36. Coprinus plicatilis, 37. Cyathus stercoreus, 38. Lepiota clypeolaria, 39. Lepiota cristata, 40. Leucocoprinus birnbaumii, 41. Macrolepiota procera, 42. Agaricus trisulfuratus, 43. Stropharia rugosoannulata, 44. Pulveroboletus auriflammeus, 


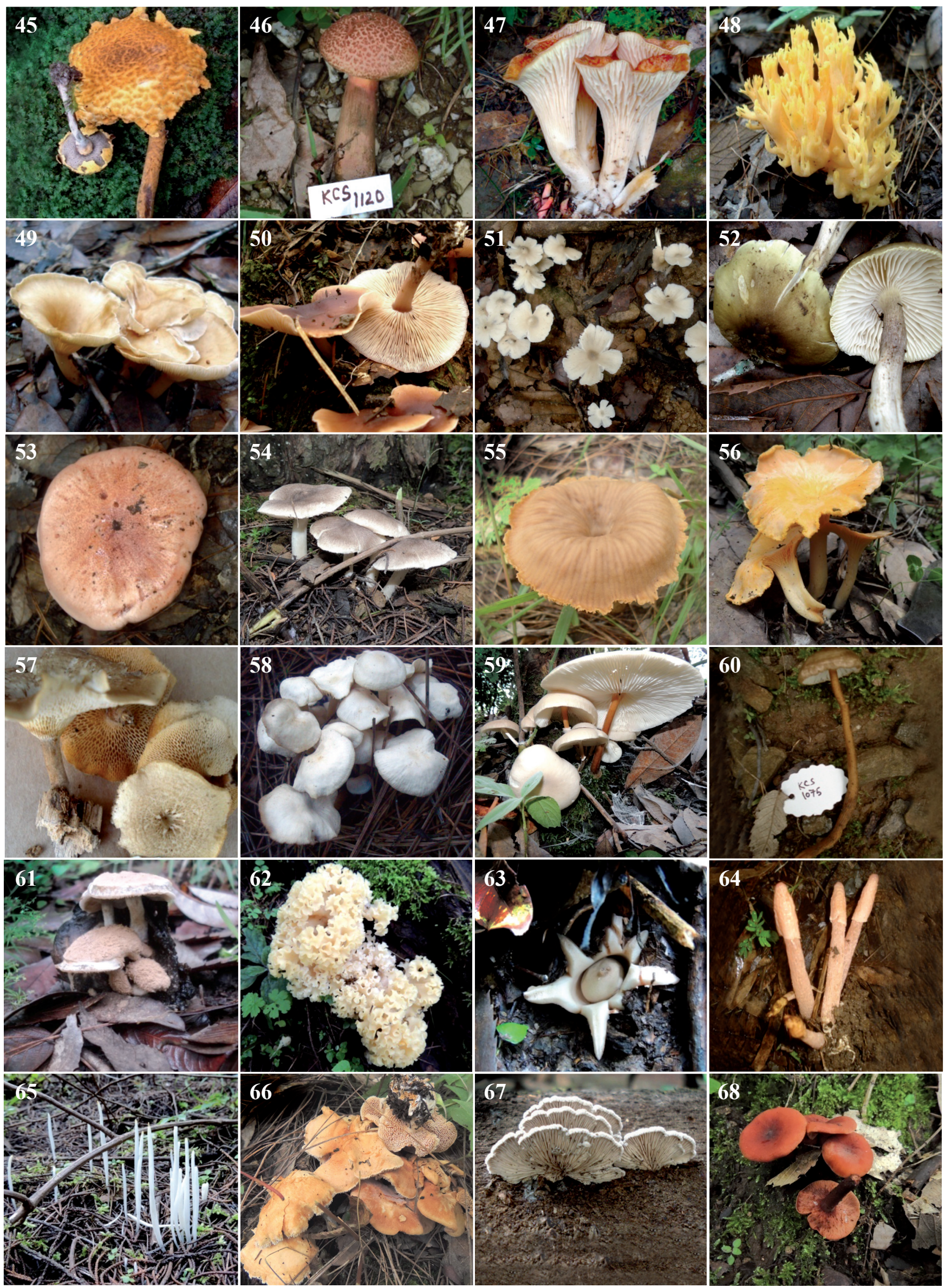

45. Strobilomyces mirandus, 46. Suillus pictus, 47. Gomphus floccosus, 48. Ramaria aurea, 49. Clitocybe gibba, 50. Collybia butyracea, 51. Termitomyces microcarpus, 52. Tricholoma saponaceum, 53. Tricholomopsis rutilans, 54. Tricholoma virgatum, 55. Laccaria laccata, 56. Cantharellus cibarius, 57. Polyporus arcularius, 58. Marasmius oreades, 59. Oudemansiella mucida, 60. Xerula radicata, 61. Asterophora lycoperdoides, 62. Sparassis crispa, 63. Geastrum saccatum, 64. Mutinus caninus, 65. Clavaria fragilis, 66. Hydnum repandum, 67. Schizophyllum communae, 68. Lactarius camphoratus 